\title{
Near-Field Opto-Chemical Sensors
}

\author{
Antonietta Buoscioloㄹ, Marco Consales², Marco Pisco², \\ Michele Giordano ${ }^{1}$ and Andrea Cusano ${ }^{2}$ \\ ${ }^{1}$ National Research Council, Institute for Composite and Biomedical Materials \\ Napoli, Italy \\ ${ }^{2}$ University of Sannio, Optoelectronic Division, Engineering Department, \\ Benevento, Italy
}

\section{Introduction}

Nanotechnology and nanoscale materials are a new and exciting field of research. The inherently small size and unusual optical, magnetic, catalytic, and mechanical properties of nanoparticles not found in bulk materials permit the development of novel devices and applications previously unavailable. One of the earliest applications of nanotechnology that has been realized is the development of improved chemical and biological sensors. Remarkable progress has been made in the last years in the development of optical nanosensors and their utilization in life science applications.

This new technology demonstrates the breadth of analytical science and the impact that will be made in the coming years by implementing novel sensing principles as well as new measurement techniques where currently none are available.

What is exciting in sensor research and development today? This is a tough question. There are many significant innovations and inventions being made daily. Micro and nanotechnology, novel materials and smaller, smarter and more effective systems will play an important role in the future of sensors.

With the increasing interest in and practical use of nanotechnology, the application of nanosensors to different types of molecular measurements is expanding rapidly. Further development of delivery techniques and new sensing strategies to enable quantification of an increased number of analytes are required to facilitate the desired uptake of nanosensor technology by researchers in the biological and life sciences.

To fulfil the promise of ubiquitous sensor systems providing situational awareness at low cost, there must be a demonstrated benefit that is only gained through further miniaturization. For example, new nanowire-based materials that have unique sensing properties can provide higher sensitivity, greater selectivity and possibly improved stability at a lower cost and such improvements are necessary to the sensor future.

Nano-sensors can improve the world through diagnostics in medical applications; they can lead to improved health, safety and security for people; and improved environmental monitoring. The seed technologies are now being developed for a long-term vision that 
includes intelligent systems that are self-monitoring, self-correcting and repairing, and selfmodifying or morphing not unlike sentient beings.

On this line of argument, in last years, our interdisciplinary group has been involved in research activities focused on the development of novel opto-chemical nano-sensors employing near-field effects to enhance the overall performance of the final device.

In this chapter, thus, we report recent findings on new class of opto-chemical sensors whose excellent sensing performance are related to an enhancement effect of the optical near-field induced by semiconductive structures of tin dioxide $\left(\mathrm{SnO}_{2}\right)$ when their spatial dimensions are comparable to the employed radiation wavelength $(\lambda)$.

The main objective is to investigate the possibility to concentrate the electro-magnetic field in precise localized spots, by means of metal oxide micro and nano-sized structures, to increase light matter interaction and provide innovative and valuable sensing mechanisms for next generation of fiber optic chemical and biological nano-sized sensors (Pisco et al., 2006; Buosciolo et al., 2006).

Due to the strong interdisciplinary nature of the problem, research activities have been carried out following an integrated approach where all the aspects (material selection, integration techniques and transducer development), have been simultaneously addressed and optimized.

Taking this line, interest was focused on issues like investigation of the surface morphology and of the near-field optical properties in relation to suitable processing and post-processing conditions; correlation of the surface layer morphology and the emerging near-field intensity distribution with the sensing performance [Consales et al., 2006b; Cusano et al., 2006). We found that sensitive layers with very rough morphologies inducing a significant perturbation of the optical near-field, exhibited surprisingly sensing performance for both water chemicals monitoring and against chemical pollutants in air environment, at room temperature (Cusano et al., 2006; Buosciolo et al., 2008b).

Similar effects of light manipulation have been observed, in recent years, only in noble metal nanostructures explained in terms of localized surface plasmons and in subwavelength hole arrays in both metal films and non metallic systems; in a recent convincing theoretical model (Lezec \& Thio, 2004) relative to the last case, the transmission of light is modulated not by coupling to surface plasmons, but by interference of diffracted evanescent waves generated by subwavelength periodic features at the surface, leading to transmission enhancement as well as suppression.

In light of this argument, it is clear that the manipulation of light through semicondutive micro and nano sized structures opens new frontiers not only in sensing applications but have also vast potential to be applied in many fields ranging from high performance nanometer-scale photonic devices up to in-fiber micro systems.

Here, we review the technological steps carried out by our group for the demonstration of a novel sensing mechanism arising from near-field effects in confined domains constituted by particle layers of tin dioxide with size approaching the optical wavelength. To this aim, we have structured the present chapter as follows: sections 2 and 3 are focused on the properties and characteristics of tin dioxide as sensing layer for chemical transducers with particular emphasis on the state of the art on chemical sensors based on this type of semiconductor. Section 4 deals with the principle of operation of the proposed reflectometric opto-chemical sensors and with the electrostatic-spray pyrolysis method as valuable tool to deposit particle layers of tin dioxide on optical fiber substrates at wavelength scale. Section 5 
reports the morphological and optical characterization of the so produced superstrates carried out by atomic force and scanning near-field optical microscopy, very useful to clearly outline the effects of processing parameters on particles size and distribution as wells on the optical near-field emerging from the overlays. Finally, in section 6 we present the sensing performances of fiber optic chemo-sensors incorporating tin dioxide particle layers in both air and liquid environments discussing the dependence of the sensing properties on film morphology and optical near-field.

\section{Tin dioxide as sensing material}

Metal oxides are widely used as sensitive materials for electrical gas sensors in environmental, security and industrial applications. The idea of using semiconductors as gas sensitive devices leads back to 1952 when Brattain and Bardeen first reported gas sensitive effects on germanium (Brattain \& Bardeen, 1952). Later, Seiyama et al. found gas sensing effect on metal oxides (Seiyama et al., 1962).

The principle of operation of such class of sensors relies upon a change of electrical conductivity of the semiconductor material as a consequence of the gas adsorption.

Even if many chemo-physical coupled phenomena, such as surface and bulk chemical reactions and mass and energy diffusion, are involved in the operation of the semiconductor solid state conductivity sensors (Lundstrom, 1996), in general, the sensing principle is dominated by the variation of the electronic properties of wide-band-gap semiconductors such as $\mathrm{SnO}_{2}$ and $\mathrm{ZnO}$ due to the gases adsorption that modifies the intrinsic electronic defect formation (Szklarski, 1989). The gas sensitivity of semiconductor materials is underlain by reversible effects resulting from chemisorption of molecules, formation of space charge areas, and variation of the concentration of the charge carriers in the subsurface layer.

Although the general principle of the detection mechanism is appreciated, the size of the change of electric conductivity (sensor signal) is largely determined by the structural type of the semiconductor, the nature and concentration of surface reactive centers, and the real structure of the material: the size, structure, and degree of agglomeration of crystallites, specific surface area, and pore geometry (Rumyantsevaa et al., 2008).

In principle, any semiconducting oxide can be exploited as a sensor by monitoring changes of its resistance during interaction with the detected gas molecules at an operating temperature typically above $200{ }^{\circ} \mathrm{C}$. Because tin oxide $\left(\mathrm{SnO}_{2}\right)$ offers high sensitivity at conveniently low operating temperatures, attention has been concentrated on this material although lately many studies extended also to other oxides.

In fact, several commercial devices based on $\mathrm{SnO}_{2}$ for detecting low concentration of both flammable, i.e. $\mathrm{CH}_{4}$ and $\mathrm{H}_{2}$, and toxic; i.e. $\mathrm{CO}, \mathrm{H}_{2} \mathrm{~S}$ and $\mathrm{NO}_{\mathrm{x}}$, gases, are available. $\mathrm{SnO}_{2}$ sensors can be referred to as the best-understood prototype of oxide based gas sensors. Nevertheless, highly specific and sensitive $\mathrm{SnO}_{2}$ sensors are not yet available. It is well known that sensor selectivity can be fine-tuned over a wide range by varying the $\mathrm{SnO}_{2}$ crystal structure and morphology, dopants, contact geometries, operation temperature or mode of operation, etc. The electric conductivity of oxide semiconductors is extremely sensitive to the composition of the surface, which reversibly varies as a consequence of surface reactions involving chemisorbed oxygen $\left(\mathrm{O}_{2}{ }^{-}, \mathrm{O}^{2-}, \mathrm{O}^{-}\right)$and the gas mixture components, proceeding at $100-500^{\circ} \mathrm{C}$. (Rumyantsevaa et al., 2008; Barsan, et al., 1999). 
Moreover, tin oxide is sensitive to both oxidizing gases, such as ozone, $\mathrm{O}_{3}$, and $\mathrm{NO}_{2}$, and reducing species, such as $\mathrm{CO}$ and $\mathrm{CH}_{4}$ (Becker, 2001). In particular, in the case of oxidizing gases the raising in conductivity upon gas-solid interaction is due to the injection into the conductivity band of electrons produced by the surface reaction between the gas and the chemically active species, $\mathrm{O}_{\mathrm{ads}}{ }^{-}$of tin oxide, as an example $\mathrm{CO}+\mathrm{O}_{\mathrm{ads}}{ }^{-} \rightarrow \mathrm{CO}_{2}+e^{-}$; while, in the case of reducing gases, the reactions consume the conduction electrons increasing the tin oxide resistivity, as an example $\mathrm{NO}_{2}+\mathrm{e}-\rightarrow \mathrm{NO}+\mathrm{O}_{\text {ads }}$.

In conclusions, the advantages offered by wide-band-gap semiconductor oxides as sensing materials include their stability in air, relative inexpensiveness, and easy preparation in the ultradispersed state (Rumyantsevaa et al., 2008). Three main drawbacks characterize such class of sensors materials: the relatively high operative temperature, the poor selectivity due to unspecificity of the contribution made by the gas phase molecules to the total electric response and the long term drift (Sberveglieri, 1995).

\section{State of the art on $\mathrm{SnO}_{2}$ based sensors}

The first great production and utilization of tin dioxide based gas sensors started in Japan from a patent (Taguchi, 1962) deposited by Naoyoshi Taguchi in the far 1962. His work was completed in the years 1968-69 when he established mass production and started selling the Taguchi Gas Sensor (TGS) and founded the "Figaro Engineering Inc." currently a world leader company in gas sensors production. The first TGS was a ceramic thick film sensor using tin-dioxide powder as sensitive element. The rapid success and the grown in the production of the TGSs in the years following the first TGS realization is attributed not only to the exhibited performances but also to the large diffusion in that years in Japan of bottled gas and the consequent numerous accidental gas explosions (Ihokura \& Watson, 1994), leading to the need of security gas sensors.

After almost fifty years since the first TGS realization, many and many technological advancements in the sensing field strongly widened the classes of available sensors both commercially and in the scientific community. Many of them are still based on tin dioxide as sensitive material.

The first generation of sensors based on tin dioxide as sensitive material was manufactured by ceramic thick film technology. In ceramic thick film sensors, the tin dioxide is most commonly sintered onto a substrate, usually of alumina (Ihokura, 1981). In operation, this substrate is heated by an electrically energized filament and the resistance of the active material, which is very high in fresh air, falls as the concentration of (combustible) contaminant gas rises (Watson, 1984).

Since thick film sensors' performance depend on percolation path of electrons through intergranular regions, by varying small details in the preparation process, each sensor differed slightly in its initial characteristics. Therefore the materials fabrication processes have been improved towards thin film technology, that offers higher reproducibility and long term stability.

In order to enhance the performances and the selectivity of these sensors, several approaches have been pursued.

An approach consists in the careful choice of the working temperature of the sensor that is able to enhance the sensitivity to certain gases by comparison with others (Fort et al., 2002). Since the optimum oxidation temperatures are different from gas to gas, operating the 
transducer at two different temperatures leads to the enhancement of the sensor selectivity (Heilig et al., 1999).

A large number of additives in $\mathrm{SnO}_{2}$, such as $\mathrm{In}, \mathrm{Cd}, \mathrm{Bi}_{2} \mathrm{O}_{3}$ and noble metals (i.e. palladium or platinum) either in thick or in thin films based sensors have been investigated to improve the selectivity and to enhance the response of the tin-dioxide gas sensors (Yamazoe, 1983). These dopants are added to improve sensor sensitivity to a particular gas, to minimize cross sensitivity to other gases and to reduce temperature of operation. Palladium inclusions, for example, leads to a lowering of the sensor resistance, a speeding up of transient behavior and modifies the selectivity characteristics of the sensor by changing the rates of the redox reactions (Watsont et al., 1993; Cirera et al., 2001). The doping of $\mathrm{SnO}_{2}$ with Pt reduces in particular the optimum operating temperature for sensing $\mathrm{CO}$ gas. On the other hand, the doping of $\mathrm{SnO}_{2}$ with trivalent additive favors the detection of oxidant gases. By suitably selecting the dopant the temperature of device operation can be tailored for a specific application (Erann et al., 2004; Ivanov et al., 2004). Other additives such as gold, rhodium, ruthenium and indium have more significant effects on selectivity, as do several metal oxides including those of lanthanum and copper.

A widely employed approach to enhance the sensor selectivity concerns exploiting different measurement techniques and/or data processing algorithms. Of course, these approaches are not limited to tin-oxide based sensors. Nonetheless, interesting results have been achieved also with tin oxide by measuring the transducer conductivity variations during chemical transients obtained with abrupt changes in target molecules concentration. In fact in this case the reaction kinetics can be exploited to differentiate among different compounds (Schweizer-Berberich et al., 2000; Llobet et al., 1997; Ngo et al., 2006).

More generally, the realization of an array of sensors with different features and the employment of pattern recognition techniques demonstrated to be a suitable strategy to discriminate among different target molecules (Gardner et al., 1992; Hong et al., 2000; Lee et al., 2001; Delpha et al., 2004).

The effect of grain size on the sensitivities of $\mathrm{SnO}_{2}$ films has been also investigated since 1991, when Yamazoe (Yamazoe, 1991) showed that reduction of crystallite size caused a huge improvement in conductometric sensor performance. In fact, in a low grain size metal oxide almost all the carriers are trapped in surface states and only a few thermal activated carriers are available for conduction. In this configuration the transition from activated to strongly not activated carrier density, produced by target gases species, has a great effect on sensor conductance. The challenge thus became to prepare stable materials with small crystallite size. This process has been assisted by the recent progress in nanotechnology, thank to which fine control over the crystallinity, morphology, composition and doping level of these sensing materials could be obtained.

An important step forward has been achieved by the successful preparation of stable single crystal quasi-one-dimensional semiconducting oxides nanostructures (the so-called nanobelts, nanowires or nanoribbons) (Pan et al., 2001; Comini et al., 2002).

This was followed by the publication of some fundamental demonstrations (Cui et al., 2001; Law et al., 2002; Arnold et al., 2003; Li et al., 2003) of detecting a variety of chemicals and bio-agents using semiconducting 1-D oxides. Since then, this area has been experiencing significant growth in the past six years and it is not yet clear whether it will reach saturation soon (Comini, 2008; Chen et al., 2008). 
In particular, $\mathrm{SnO}_{2}$ nanowires and nanobelts have been widely reported in a number of reports as conductometric chemical sensors, both in normal resistor or in Field Effect Transitor (FET) configurations (Maffeis et al., 2002; Panchapakesan et al., 2006; Helwig et al., 2007). The first $\mathrm{SnO}_{2}$ nanobelt chemical sensor was realized in 2002 and employed for the detection of $\mathrm{CO}, \mathrm{NO}_{2}$, and ethanol (Comini et al., 2002). It relied on simple DC-resistive measurements and was made by dispersing $\mathrm{SnO}_{2}$ nanobelts atop platinum interdigitated electrodes, prefabricated on an alumina substrate. In 2005, the possibility to integrate tin oxide nanobelts with micro-machined substrate has been proved by $\mathrm{Yu}$ et al. ( $\mathrm{Yu}$ et al., 2005), that reported on a single- $\mathrm{SnO}_{2}$-nanobelt sensor integrated with microheaters to sense dimethyl methylphosphonate (DMMP), a nerve agent stimulant. Recently, Wan et al. (Wan et al., 2008) proposed a high-performance ethanol sensor based on branched $\mathrm{SnO}_{2} / \mathrm{Sb}$-doped $\mathrm{SnO}_{2}$ nanowire films.

Chemical sensors based on metal oxide 1-D structure configured in FET devices have also been extensively studied. For example, Law et al. (Law et al., 2002) published a contribution on the room temperature $\mathrm{NO}_{2}$ sensing properties of a FET sensor based on a single crystalline tin oxide nanowire. They made use of UV light, that has proven to be effective also with thin films (Comini et al., 2001), to improve adsorption and desorption process. Zhang et al. (Zhang et al., 2004) also presented some experiments on $\mathrm{SnO}_{2}$ single nanowire sensor in a FET structure in pure nitrogen, nitrogen-oxygen and nitrogen-oxygen-CO atmospheres.

Enhanced performances have also been demonstrated in the last years with 1-D $\mathrm{SnO}_{2}$ nanostructure-based conductometric sensors with Pd (Kolmakov et al., 2005), Ag (Chen \& Moskovits, 2007), Ni (Sysoev et al., 2006) and Au (Qian et al., 2006) nanoparticles decorated on the surface of nanowires and nanobelts.

The main disadvantage of conductometric sensors is their need for a high working temperature, which leads to power wastage. Recently, some contribution on new (and yet not well explored) optical detection methods have also been proposed for the realization of tin oxide chemical sensors. They are based on the measurements of optical response of $\mathrm{SnO}_{2^{-}}$ based materials to environmental changes, instead of the electrical ones. In particular, some contributions have been reported on the quenching in the visible photoluminescence (PL) of tin oxide nanostructures due to the introduction of $\mathrm{NO}_{2}, \mathrm{NH}_{3}$, and $\mathrm{CO}$ in dry and humid synthetic air and normal ambient pressure conditions (Faglia et al., 2005; Baratto et al., 2005; Setaro et al., 2008).

Also, in the last few years, $\mathrm{SnO}_{2}$ was exploited as sensitive wavelength-scale particle layers for the realization of a new concept near-field fiber optic chemical sensors able to work at room temperature, either in air or water environments (Cusano et al., 2006; Buosciolo et al., 2008b). The electrostatic spray pyrolysis was exploited to transfer $\mathrm{SnO}_{2}$ thin films composed of grains with wavelength and subwavelength dimensions atop the termination of standard optical fibers (Pisco et. al, 2006). This layer morphology demonstrated to be very promising for optical sensing because it is able to significantly modify the optical near-field profile emerging from the film surface. As matter of fact, local enhancements of the evanescent wave contribute occurs leading to a strong sensitivity to surface effects induced as consequence of analyte molecule interactions (Cusano et al., 2007). 


\section{Tin dioxide opto-chemical nano-sensors}

\subsection{Principle of operation}

For the realization of the proposed near-field opto-chemical sensors, the reflectometric configuration has been exploited (Pisco et al., 2006). It is essentially based on a modified extrinsic Fabry-Perot (FP) interferometer which, as schematically represented in Fig. 1, uses a microstructured tin dioxide sensitive film deposited at the distal end of a properly cut and prepared optical fiber.

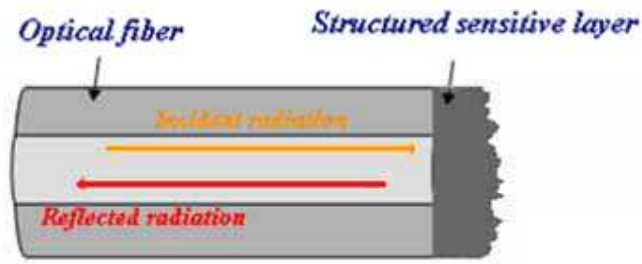

Fig. 1. Schematic view of the reflectometric configuration.

In line of principle, the key point of this configuration is the dependence of the reflectance at the fiber/sensitive layer interface on the optical and geometric properties of the sensitive materials. In particular, the interaction with target analyte molecules promote changes in the chemo-optic features of the active layers surface, basically its dielectric constant. In this case in fact, contrarily to what happen for the standard FP configurations (Pisco et al., 2006), the interaction of the field with the chemicals present within the atmosphere occurs not in the volume of the layer but mainly on its surface by means of the evanescent part of the field, promoting a significant improvement of the fiber optic sensor performance. The chemooptic variations induced by the surface-chemicals interaction lead to changes in the film reflectance and thus in the intensity of the optical signal reflected at the fiber/film interface. As we will see in the section 6.1 , this optical intensity modulation is simply detectable by means of single-wavelength reflectance measurements.

\subsection{Integration of sensing layers with standard optical fibers}

Many sensitive materials and transducing techniques are today available to develop optochemical sensors, but it's necessary to find the suitable deposition technique, depending on the nature of the material and the transducing substrate, in order to control the morphological and geometrical features of the sensitive layer. This governance is, in fact, essential to fully benefit of the materials properties and to be able to mathematically schematize the sensor for a reasonable design of its performances. Hence, the challenge in this field is not just relating to the chemical tailoring of the material properties, but also the integration of the material with the sensing platform. At the same time simple and low cost fabrication procedure and equipment are mandatory for a fast and cost-effective evolution of the devices from laboratories to market.

In the following, a brief introduction to the Electrostatic Spray Pyrolysis (ESP) technique and a description of its optimization and customization for the deposition of the selected sensitive material onto the fiber substrates are presented. 
Moreover, the possibility to obtain thin films at nano and micro scale and to tailor the sensitive layers features by properly changing the ESP deposition parameters will also be reported.

\subsection{Electrostatic Spray Pyrolysis (ESP) deposition technique}

The spray pyrolysis technique has been, during the last three decades, one of the major techniques to deposit a wide variety of materials in thin film form (Perednis \& Gauckler, 2005). Unlike many other film deposition techniques, spray pyrolysis represents a very simple and relatively cost effective processing method (especially with regard to equipment costs). It offers an extremely easy technique for preparing films of any composition and it does not require high quality substrates or chemicals. The method has been employed for the deposition of dense films, porous films, and for powder production. Even multilayered films can be easily prepared using this versatile technique.

Thin metal oxide and chalcogenide film deposited by spray pyrolysis and different atomization techniques were reviewed for example by Patil (Patil, 1999).

ESP is a spray deposition technique in which the precursor solutions are electrosprayed toward substrates from the end of a highly biased metal capillary (typically 5-25 kV).

In fact, this methodology is based on the phenomenon of electrolyte (usually ethanol or water solutions of metal chlorides) polarization on charged droplets by an electrostatic field, applied between a vessel provided with a metal capillary and a heated substrate. The polarized droplets separate one from each other by means of repulsive forces and they are carried by electrostatic field along its force lines (Higashiyama et al., 1999). The moving droplets form a cone in the space, called Tailor's cone. The substrate coverage by droplets is quasi uniform in terms of amount of drops per square unit. When droplets of solution reach the heated substrate (the substrate temperature is usually in the range $300-450^{\circ} \mathrm{C}$ ), chemical reaction of metal chloride with solution water vapor, stimulated by the temperature, takes place with formation of the oxide film (Matsui et al., 2003):

$$
\mathrm{MCl}_{\mathrm{x}}+\mathrm{x} / 2 \mathrm{H}_{2} \mathrm{O} \rightarrow \mathrm{MO}_{\mathrm{x} / 2}+\mathrm{xHCl}
$$

Thereby, metal oxide layer grows due to the thermal transformation of metal chloride to metal oxide as a consequence of the interaction with water vapor.

It's evident from this brief description that ESP involves many processes occurring either simultaneously or sequentially. The most important of these are aerosol generation and transport, solvent evaporation, droplet impact with consecutive spreading, and precursor decomposition. The deposition temperature is involved in all mentioned processes, except in the aerosol generation. Consequently, the substrate surface temperature is the main parameter that determines the electrical properties of the layers, like resistivity and charge carrier mobility, and structural properties like crystalline size and surface morphology.

For instance, for $\mathrm{SnO}_{2}$ samples deposited at higher temperatures, low resistivity and higher roughness were observed, whereas for films deposited at temperatures less than $340^{\circ} \mathrm{C}$ high resistivity, lower crystalline size and less ratio of polycrystalline phase were found (Patil et al., 2003). A more recent work of Ghimbeu et al. (Ghimbeu et al., 2007), report on the influences of deposition temperature on the surface morphology of $\mathrm{SnO}_{2}$ and $\mathrm{Cu}$-doped $\mathrm{SnO}_{2}$ thin films. Dense films with a smooth surface characterized by several cracks were deposited at low temperature such as $150^{\circ} \mathrm{C}$; denser films comprised of large particle of about $1 \mu \mathrm{m}$, which are agglomerates of small particles, were obtained at $250^{\circ} \mathrm{C}$; while films 
prepared at 350 and $400^{\circ} \mathrm{C}$ showed a porous structure and a surface roughness that increase with increasing temperature.

The precursor solution is the second important process variable. Solvent, type of salt, concentration of salt, additives and sprayed volume influence the physical and chemical properties of the precursor solution. Therefore, structure and properties of a deposited film can be tailored also by changing the precursor solution.

For example, porous $\mathrm{SnO}_{2}$ and $\mathrm{SnO}_{2}-\mathrm{Mn}_{2} \mathrm{O}_{3}$ films were prepared using the ESP deposition technique and employed in Taguchi type hydrogen sensors (Gourari et al., 1998; Gourari et al., 1999). The grain size of the porous films ranged from 1 to $10 \mu \mathrm{m}$. It was observed that the grain size increases with a higher concentration of the precursor in the ethanol solvent.

Thin $\mathrm{SnO}_{2}$ films for gas sensors were also prepared by spray pyrolysis using an inorganic as well as an organic precursor solution (Pink et al., 1980). Smooth but not very uniform films were obtained using a solution of $\left(\mathrm{NH}_{4}\right)_{2} \mathrm{SnCl}_{6}$ in water. On the other hand, very uniform but relatively rough films were deposited using a solution of $\left(\mathrm{CH}_{3} \mathrm{COO}\right)_{2} \mathrm{SnCl}_{2}$ in ethylacetate. Suitable electric properties were measured for films obtained from the organic solution. The sensitivity and rise time were found to depend on the deposition temperature and the type of precursor solution used. The best results were achieved by spraying an organic precursor solution onto a substrate at about $300^{\circ} \mathrm{C}$.

The first attempts to prepare $\mathrm{SnO}_{2}$ layers using the ESP were carried out by Gourari et al. (Gourari et al., 1998) and Zaouk et al. (Zaouk et al., 2000). Although conductive substrates were conventionally used in ESP, Zaouk et al. (Zaouk et al., 2000) revealed the availability of ESP for the insulator substrate. They investigated the electrical and optical properties of the fluorine doped $\mathrm{SnO}_{2}$ layers sprayed on Corning 7059 substrates.

\subsection{Customization and optimization of ESP deposition technique}

The ESP technique was used for the first time for the deposition of a tin dioxide layer upon the distal end of standard silica optical fibers (SOFs) by the authors in the 2005 (Pisco et., 2005). To this purpose, an optimization and customization of the standard ESP method was used. For the $\mathrm{SnO}_{2}$ particle layers deposition, single mode optical fibers were prepared by stripping the protective coating a few centimeters from the fiber-end. The bare fiber were washed in chloroform in order to remove any coating residuals. Then the fiber-end were properly cut, by using a precision cleaver, in order to obtain a planar cross-section, where the $\mathrm{SnO}_{2}$ films were deposited. A schematic view of the experimental set-up used for the sensors fabrication is shown in Fig. 2.

It consists of a high voltage source (FUG, $0-30 \mathrm{kV}$ ), two syringes connected with a flexible pipe for the solution handling, a needle with an external diameter of $0.5 \mathrm{~mm}$, connected with a high voltage source $(17 \pm 0.1 \mathrm{kV})$ in order to create a high electric field between the needle itself and a grounded metal substrate where the fiber-end is located. The necessary temperature has been reached by means of a resistive heater, in contact with the substrate, constituted by two stainless steel plates of a few square centimeters and by a nichrome wire connected with a $300 \mathrm{~W}$ voltage source. The heater was supplied with a chromium-nickel thermocouple connected with a multimeter for the temperature monitoring. The distance between the needle and the optical fiber-end was about $30 \mathrm{~mm}$. 


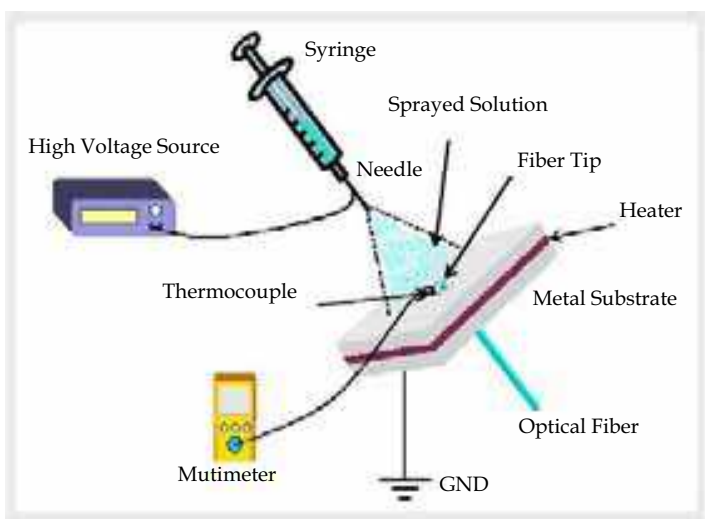

Fig. 2. Schematic view of the experimental set-up used for the deposition of the sensitive layer onto the optical fibers.

The deposition was performed at a constant temperature of $320 \pm 5^{\circ} \mathrm{C}$. Liquid flow has been regulated by means of an air pump connected with the first syringe. Tin dioxide films are grown according to the following reaction:

$$
\mathrm{SnCl}_{4}+2 \mathrm{H}_{2} \mathrm{O} \rightarrow \mathrm{SnO}_{2}+4 \mathrm{HCl}
$$

The $\mathrm{SnO}_{2}$ layers fabrication was performed by means of a constant volume, $5 \mathrm{ml}$, of an ethanol solution of $\mathrm{SnCl}_{4} \cdot 5 \mathrm{H}_{2} \mathrm{O}$ at two different concentrations: 0.01 and $0.001 \mathrm{~mol} / \mathrm{l}$.

During the deposition, it is also possible the formation of amorphous $\mathrm{SnO}$ phase. Thermal treatment is one of the ways to transform $\mathrm{SnO}_{x}$ to $\mathrm{SnO}_{2}$ and clean the films surface from the other dopants like water or alcohol present in the initial solution (Ramamoorthy et al., 2003). For this reason, after the deposition procedure, the prepared samples were annealed at $500 \pm 5^{\circ} \mathrm{C}$ for 1 hour. The temperature was increased from room temperature to $500^{\circ} \mathrm{C}$ with a constant rate of $5^{\circ} \mathrm{C} / \mathrm{min}$ and, after the annealing procedure, the temperature was decreased with the same rate down to the room temperature.

\section{Characterization of the surface morphology and of the transmitted optical field in near proximity of the overlays}

As described in the previous section 4.1, the principle of operation of the proposed sensors relies on the dependence of the reflected power at the fiber end on the optical and geometric properties of the layer itself. The interaction of the analyte molecules with the sensitive overlay leads to changes in its complex dielectric function and, in turn, in the amount of reflected power. So it's clear that the heart of a chemical sensor is the sensitive layer and for this reason a strong effort was devoted to investigate the properties of the deposited $\mathrm{SnO}_{2}$ films in terms of the surface morphology and the optical behaviors by means of scanning probe microscopy.

In the present section, we first introduce something about the above mentioned characterization technique and the employed experimental apparatus; then we report on the influence of surface features on the transmitted optical field in near proximity of the 
overlays; finally we describe how, by acting on the deposition parameters and on thermal annealing, it is possible to obtain layers able to manipulate light at sub wavelength level.

In particular, we will show that: the near-field collected in presence of $\mathrm{SnO}_{2}$ layers with a smooth topography and a surface roughness of the order of tens of nanometers, has the typical Gaussian shape of the fundamental mode propagating through the single-mode optical fiber; in presence of layers characterized by several $\mathrm{SnO}_{2}$ grains, with mean spatial dimensions greater than about $500 \mathrm{~nm}$, the near-field profile results to be significantly modified in correspondence of them; finally, layers characterized by the presence of isolated microstructures, with dimensions comparable to radiation wavelength, reveal high capability of near-field enhancement combined with a strong increasing of the evanescent wave content.

\subsection{Scanning probe microscopy}

Atomic force microscopy (AFM) and scanning near-field optical microscopy (SNOM) analyses were performed on the deposited $\mathrm{SnO}_{2}$ films, before employing them in sensing applications; as we will see in the following, neither any damage was produced nor any treatment was necessary in order to perform this kind of analysis.

The invention of scanning tunneling microscopy in 1981 began a revolution in microscopy, which has led to a whole new family of microscopies (Meyer et al., 2003), known collectively as scanning probe microscopy (SPM), among them AFM and SNOM. SPMs do not use lenses to produce the magnified image; instead, a local probe is scanned over the surface of the specimen and measures some physical property associated with the surface. This local probe is fabricated from a material appropriate for the measurement of the particular surface property. The scanning process is simply mechanical, but with extremely high precision and without producing any damage of the specimen. Moreover, SPM is capable of imaging all kind of specimen (including soft materials and biomolecular systems) at submolecular resolution, without the need for staining or coating, in a range of environments including gas and liquid, so offering major advantages over other forms of microscopy.

In Fig. 3 it is reported the AFM-SNOM system employed for the surface morphology and optical properties characterization; in fact, it is capable of simultaneous SNOM and normal force AFM imaging using the same probe (Buosciolo et al., 2006).

The super-resolution of SNOM is achieved via a sub-wavelength aperture placed in the near-field of the sample: a tapered optical fiber coated with $150 \mathrm{~nm}$ of a metal. Measurements were carried out in collection mode using a Cr/Al-coated fiber with $200 \mathrm{~nm}$ aperture diameter and illuminating the fiber under investigation with a superluminescent diode (central wavelength $\lambda_{1}=1310 \mathrm{~nm}, \lambda_{2}=1550 \mathrm{~nm}$ ). The tip was maintained in the nearfield of the sample surface using optically detected normal force feedback. This was accomplished by oscillating the tip and detecting the scattered light from a laser focused onto the end of the tip. As the tip approaches the surface, the signal decreases and a feedback circuit can be used to maintain a constant tip-sample distance while scanning the sample under the tip. During the imaging scan, the probe collects the light coming out of the sample exactly at the end face. In this way, the optical intensity distribution from the fiber end face is mapped into a SNOM image and an independent AFM normal force image is recorded simultaneously by the feedback signal that produces a three-dimensional image of the $\mathrm{SnO}_{2}$ film surface. 


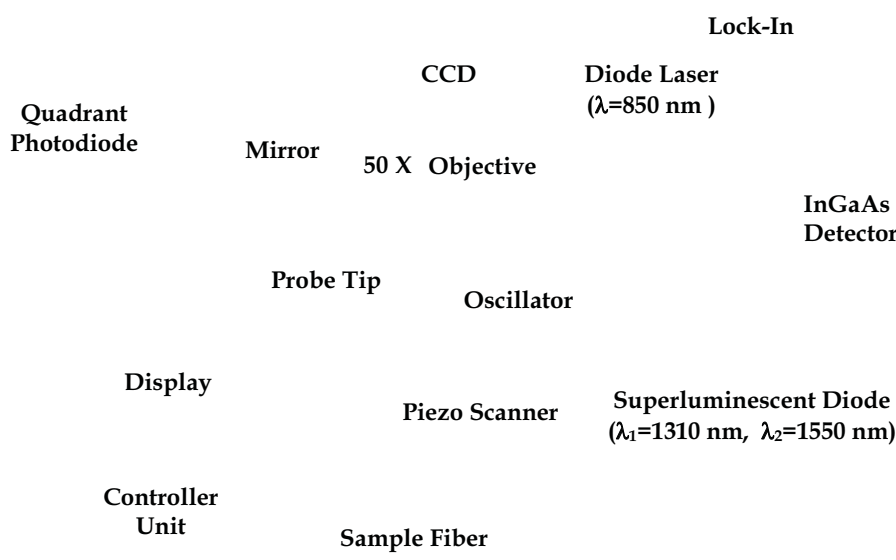

Fig. 3. Scanning probe system: simultaneous atomic force (AFM) and scanning near-field optical microscopy (SNOM).

The resolution of SNOM images is limited by the aperture size of the probe $(200 \mathrm{~nm})$; as regards the AFM characterization, in the $\mathrm{x}$ and $\mathrm{y}$ directions, the resolution is limited by the effective dimension of the terminal part of the probe (aperture diameter plus the metallization layer), while in the $z$ direction is only limited by external vibrations.

All images were obtained in air using tapping mode operation and in a region approximately centered onto the fiber core. Moreover, image acquisition times were between 30 and $40 \mathrm{~min}$ for images with pixel resolution of 256x256.

Images were processed by WSxM free software downloadable at http:www.nanotec.es. In particular, topographic images were flattened, off-line, using zero-or-first order polynomial fits to account for $\mathrm{z}$ offsets and sample tilt.

\subsection{Influence of surface layer morphology on the near-field intensity distribution}

AFM and SNOM measurements allow to obtain quantitative information on the surface structures of the sensitive coatings and the knowledge of the relationship between the layer morphology and the optical near-field collected in the close proximity of the fabricated probes (Consales et al. 2006).

As an example, in Fig.4 (a) is reported the typical bi-dimensional (2D) image of a $\mathrm{SnO}_{2}$ layer (sample A) deposited upon the distal end of the optical fiber, by ESP technique using a solution volume of $5 \mathrm{ml}$ of ethanol solution of $\mathrm{SnCl}_{4} \cdot 5 \mathrm{H}_{2} \mathrm{O}$ with a concentration of 0.01 $\mathrm{mol} / \mathrm{l}$. The image refers to a $(12 \times 12) \mu \mathrm{m}^{2}$ area, approximately centered on the optical fiber core, indicated with the green circle.

The most important measurement of surface roughness can be given with a statistical parameter: the root mean square (RMS) roughness that is the standard deviation of the height values within a given area. Figure 4 (a) reveals that the deposited layer is very smooth with a RMS roughness of about $27.98 \mathrm{~nm}$. In addition, Fig. 4 (b) shows that the 
shape of the electromagnetic field collected in the close proximity of the film surface is not influenced by the presence of such $\mathrm{SnO}_{2}$ layer, as demonstrated by the fact that it assumes the typical Gaussian profile of the field emerging from the cleaved end of a single mode optical fiber.
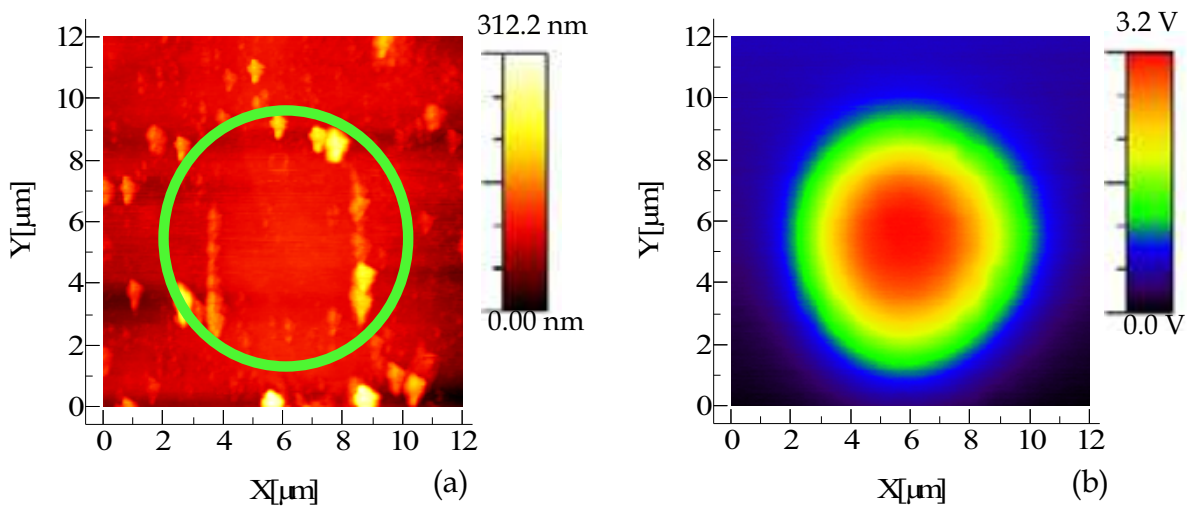

Fig. 4. Topographic image of the sample A (a) and optical near-field simultaneously collected by the SNOM probe in the same region $(12 \times 12) \mu \mathrm{m}^{2}(\mathrm{~b})$.

Different morphologies of the $\mathrm{SnO}_{2}$ particles layers can be obtained by changing the parameters of the ESP deposition process, such as the concentration and the volume of the ethanol solution of $\mathrm{SnCl}_{4} \cdot 5 \mathrm{H}_{2} \mathrm{O}$, the alignment of the optical fiber end under the needle from which the precursor solution is sprayed or the substrate temperature during the deposition. As matter of the fact, Fig. 5 (a) shows the 2D image of another tin dioxide particles layer, sample $\mathrm{B}$, fabricated by means of the same deposition parameters $(5 \mathrm{ml}$ of ethanol solution of $\mathrm{SnCl}_{4} \cdot 5 \mathrm{H}_{2} \mathrm{O}$ with a concentration of $0.01 \mathrm{~mol} / \mathrm{l}$ ) except for the fact that it was differently aligned under the syringe needle.

It can be observed that a very different morphology and, as a consequence, optical near-field profile, have been obtained. In this case, in fact, the sensitive layer exhibits an highly rough surface characterized by the presence of a number of tin dioxide grains which cause an increase of the RMS roughness up to $136.65 \mathrm{~nm}$. By an analysis of the heights and sizes distributions of the grains, a mean height of approximately $400 \mathrm{~nm}$ and mean lateral $(\mathrm{x}, \mathrm{y})$ dimension of approximately $465 \mathrm{~nm}$ were estimated.

Fig. 5 (b) reveals that, in this case, the optical profile of the emergent near-field is significantly influenced by such overlay morphology. As matter of fact, the Gaussian shape of the near-field collected in the close proximity of the layer surface, appears modified in correspondence of the $\mathrm{SnO}_{2}$ grains with dimensions comparable with the light wavelength. In fact, relatively to the core region only, the biggest grains able to produce a perturbation of the field have a mean height of about $700 \mathrm{~nm}$ and a mean width of about $550 \mathrm{~nm}$. 

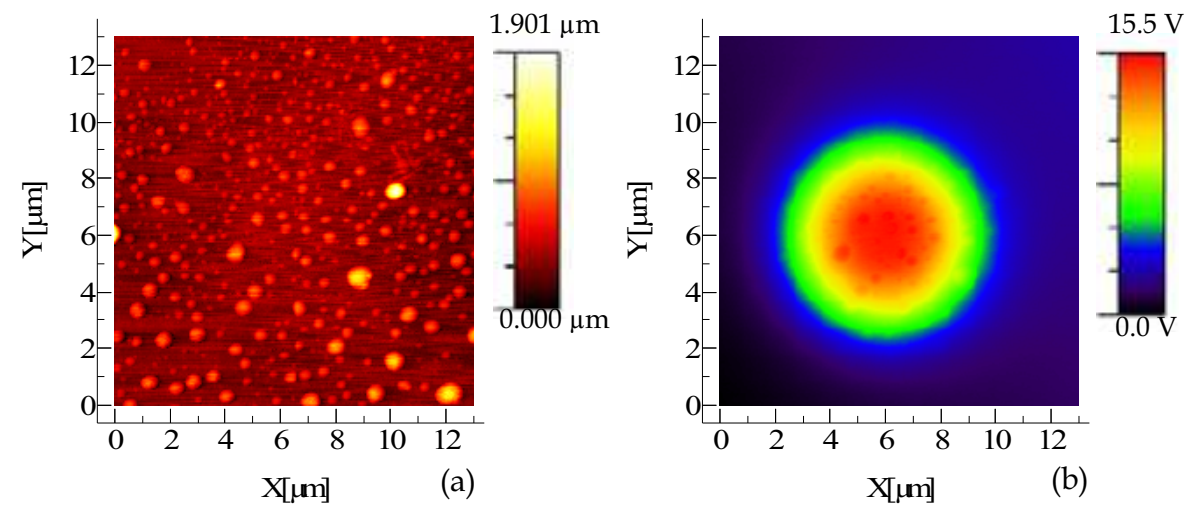

Fig. 5. Topographic image of the sample B (a) and optical near-field simultaneously collected by the SNOM probe in the same region $(13 \times 13) \mu \mathrm{m}^{2}(\mathrm{~b})$.

It was demonstrated that this effect can be attributed to the high refractive index of the $\mathrm{SnO}_{2}$ grains (approximately 1.967 for $\lambda=1550 \mathrm{~nm}$ ) which try to guide the light but, the lateral dimensions and the grains spacing (mean grains spacing is about $1 \mu \mathrm{m}$ ) are too small to allow a correct light localization due to the significant overlap of the evanescent field. This interpretation was confirmed by additional experiments focused on the investigation of the particle layer effects in the case of larger and isolated grains (Cusano et al., 2007).

In fact, the near filed enhancement effect was observed for the first time by the authors in 2007 (Cusano et al., 2007) in the case of $\mathrm{SnO}_{2}$ grains whose spatial dimensions approach the radiation wavelength.

Here, we report the case of the sample $\mathrm{C}$ obtained in the same deposition condition of sample $\mathrm{A}$, but using a different concentration of ethanol solution of $\mathrm{SnCl}_{4} \cdot 5 \mathrm{H}_{2} \mathrm{O}$ equal to $0.001 \mathrm{~mol} / \mathrm{l}$. As it is possible to note from the 2D representation of sample $\mathrm{C}$ topography reported in Fig. 6 (a), the isolated microstructure has approximately the shape of an half ellipsoid, with dimensions $\mathrm{x} \approx \mathrm{y} \approx 1.4 \mu \mathrm{m}$ and $\mathrm{z} \approx 1.0 \mu \mathrm{m}$, on a flat $\mathrm{SnO}_{2}$ substrate. It is evident from Fig. 6 (b) that the optical near-field is strongly enhanced in correspondence of the such grain. The local intensity enhancement, calculated as the ratio between the maximum measured intensity and the corresponding intensity of the unperturbed field is about 1.8. (Cusano et al., 2007).

In order to demonstrate that the field enhancement is observable only in the near-field range, the emergent field at a constant sample-probe distance of approximately $2 \mu \mathrm{m}$, was also recorded, as reported in Fig. 7 (a).

For a sample-tip distance comparable to the optical wavelength, the field profile is not able to completely maintain information about the film morphology, even if a significant distortion of the beam shape is still clearly observable in Fig. 7 (a). By increasing the sampletip distance, up to few times the wavelength the collected optical field profile assumes the Gaussian shape, as expected in far field imaging.

Moreover, it was possible to construct a map of the radiation intensity coupled into the standard optical fiber coated with the $\mathrm{SnO}_{2}$ overlay simply by coupling the cantilevered 
optical probe to the superluminescent diode and the fiber sample to the InGaAs detector (named reverse configuration, compared to the forward one reported in Fig. 3).

It was found that the profile of the radiation intensity coupled to the sample fiber using the reverse configuration, reported in Fig. 7 (b), is very similar to that one transmitted through the optical fiber coating and collected in the forward configuration (Fig. 6 (b)). In this case the local intensity enhancement is about 1.5 calculated using the same procedure reported above in the text.
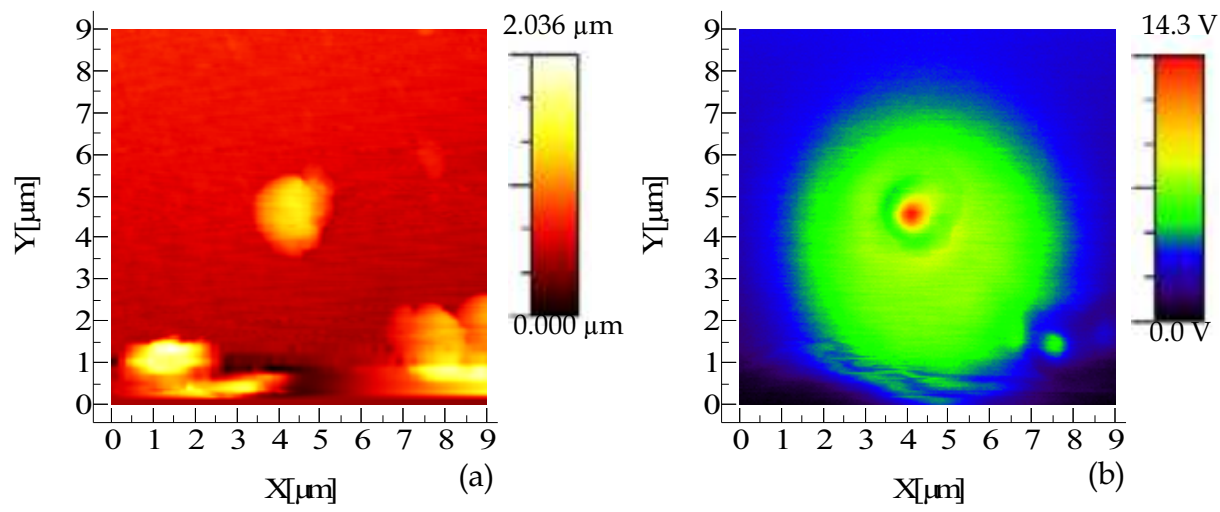

Fig. 6. Topographic image of the sample $C$ (a) and optical near-field simultaneously collected by the SNOM probe in the same region $(9 \times 9) \mu \mathrm{m}^{2}(\mathrm{~b})$.
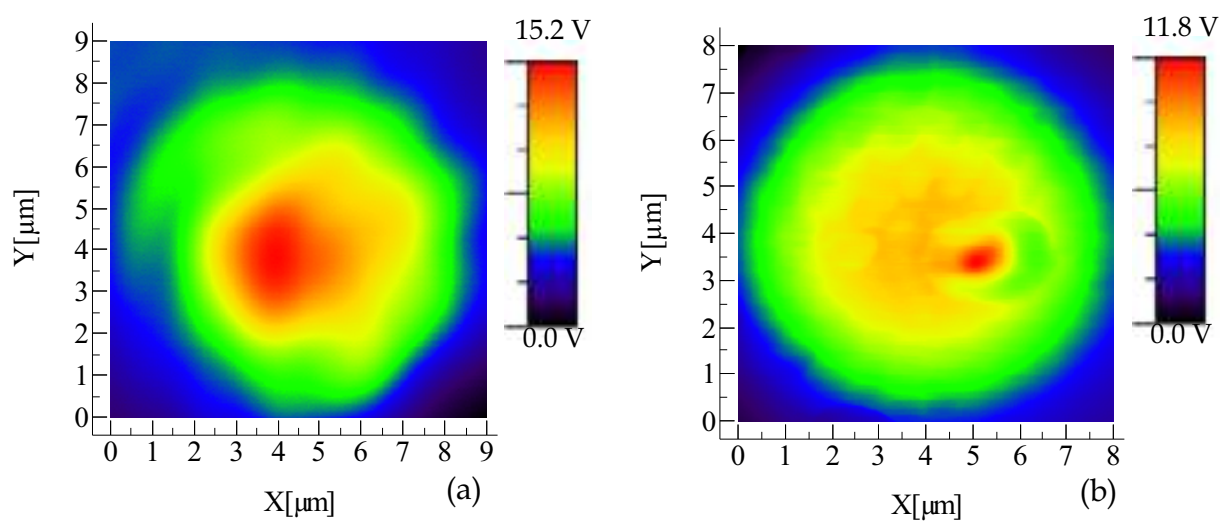

Fig. 7. Emergent field collected from the sample $C$ at constant sample-tip distance of about 2 $\mu \mathrm{m}$ (a) and radiation intensity coupled into the standard optical fiber when it was illuminated by the SNOM probe (b).

In light of these experimental results, the authors were able to give an effective explanation of the observed phenomenon: the radiation impinging at the base of the grain, coming from the layer of the same material, continues to propagate inside of it (confined by the high 
refractive index contrast between the oxide and the air and by the geometry of the grain), and near the grain surface a significant part of the propagative field becomes evanescent. Moreover, since the structure dimensions are comparable to the radiation wavelength (as revealed from AFM measurements) it is possible to state that the local field enhancement is not due to truly evanescent field. In fact, the reverse profile is very similar to that one obtained in forward configuration indicating a strong reciprocity not compatible with a structure able to convert at its ends (due to diffraction limit) all the propagating contribute in the evanescent counterpart.

In other words, the particular microstructures found on the core of the fibers showed a high capability of locally enhance the optical near-field. The observed phenomenon lead to foresee the possibility to develop a new concept of $\mathrm{SnO}_{2}$-transducer based on a surface localized interaction of the optical near-field with chemicals, named by the authors nearfield opto-chemical sensors.

In this framework, we demonstrated the capability of the developed near-field optochemical sensors to detect very low concentrations of toluene and xylene in air environment and also of ammonia molecules in water, at room temperature.

In particular, a comparison between the sensing performance of $\mathrm{SnO}_{2}$-based sensors characterized by almost flat (unable to influence the near-field) and peculiar rough surfaces (able to perturb the near-field) will be reported to demonstrate that sensitive layers able to strongly enhance the optical near-field have the best sensing characteristics, either in terms of sensitivity and responses dynamics (Cusano et al., 2006; Consales et al., 2007a; Buosciolo et al., 2008b).

\subsection{Effect of the processing parameters}

As mentioned in the section 4.3 , it was shown in literature that the concentration of the sprayed solution plays an important role in the film surface morphology. Since the overlay topography determines the near-field properties, the effect of such process variable and the influence of post processing thermal treatment on the overlay morphology were investigated by the authors; the obtained results were collected in some recent reports (Consales et al., 2006b; Buosciolo et al., 2008a; Buosciolo et al., 2008b).

To this aim, two groups of samples were fabricated by using different solution concentration: $0.001 \mathrm{~mol} / \mathrm{l}$ and $0.01 \mathrm{~mol} / \mathrm{l}$.

Here, for the sake of simplicity, the description relative to only two samples belonging to the mentioned groups is reported. The full description of the two groups of samples can be found in the cited article (Buosciolo et al., 2008b).

In Fig. 8 (a) and (c) the typical 2D height images of two $\mathrm{SnO}_{2}$ layers (sample $\mathrm{D}$, sample E) prepared by using a solution volume of $5 \mathrm{ml}$ of ethanol solution of $\mathrm{SnCl}_{4} \cdot 5 \mathrm{H}_{2} \mathrm{O}$ with a concentration of $0.001 \mathrm{~mol} / \mathrm{l}$, are reported.

Figures 8 (b) and (d) demonstrate that the most pronounced modification of the typical Gaussian profile, emerging from standard single mode optical fibers, occurs in correspondence of the sample D. In fact, the structures dimensions approach the optical wavelength $(1550 \mathrm{~nm})$ and the structures spacing is large enough to make possible an effective light localization in the high refractive index $\mathrm{SnO}_{2}$ grains (Cusano et al., 2007).

In Fig. 9 (a) and (c) the typical 2D height images of two $\mathrm{SnO}_{2}$ layers (sample F, sample G) prepared by using a solution volume of $5 \mathrm{ml}$ of ethanol solution of $\mathrm{SnCl}_{4} \cdot 5 \mathrm{H}_{2} \mathrm{O}$ with a concentration of $0.01 \mathrm{~mol} / \mathrm{l}$, are reported. 

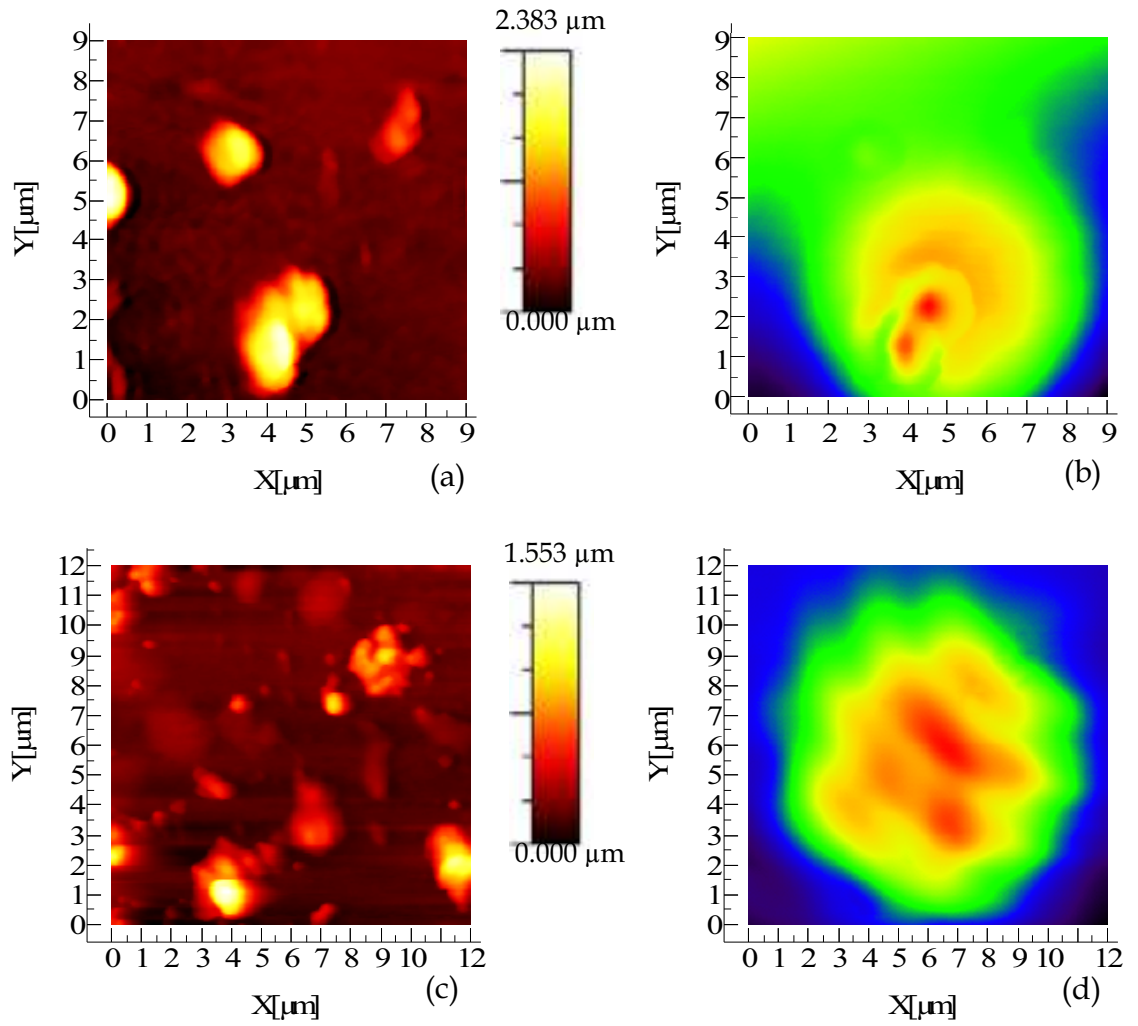

$11.8 \mathrm{~V}$

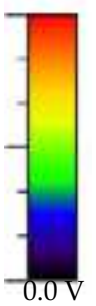

Fig. 8. AFM topographic images (a), (c) and near-field intensity simultaneously collected by the NSOM probe (b), (d) on the sample D and E respectively, prepared using a solution concentration of $0.001 \mathrm{~mol} / \mathrm{l}$, before annealing process.

Sample F topography (see Fig. 9 (a)) is characterized by the presence of several grains, but with no regular shape. The major part of them have lateral dimensions smaller than $500 \mathrm{~nm}$ and a mean height of the order of $150 \mathrm{~nm}$, while few others have mean lateral dimensions of the order of $1 \mu \mathrm{m}$ and a mean height of $300 \mathrm{~nm}$. There is only one microstructure whose characteristic dimensions are $\mathrm{a} \approx 1430 \mathrm{~nm}, \mathrm{~b} \approx 1900 \mathrm{~nm}$ and $\mathrm{h} \approx 450 \mathrm{~nm}$.

Sample G topography (see Fig. 9 (c)) presents several structures of rectangular shape whose lateral dimensions $\mathrm{a}$ and $\mathrm{b}$ vary in the following range: $\mathrm{a} \in(2.3 \div 3.4) \mu \mathrm{m}, \mathrm{b} \in(3.4 \div 4.8) \mu \mathrm{m}$, while the average height is about $4.0 \mu \mathrm{m}$.

Figures 9 (b) and (d) demonstrate that the most pronounced modification of the near-field profile occurs in correspondence of the sample G.

The conclusion is that increasing the metal chloride concentration it is possible to obtain a more structured surface morphology able to significantly influence the optical near-field. 


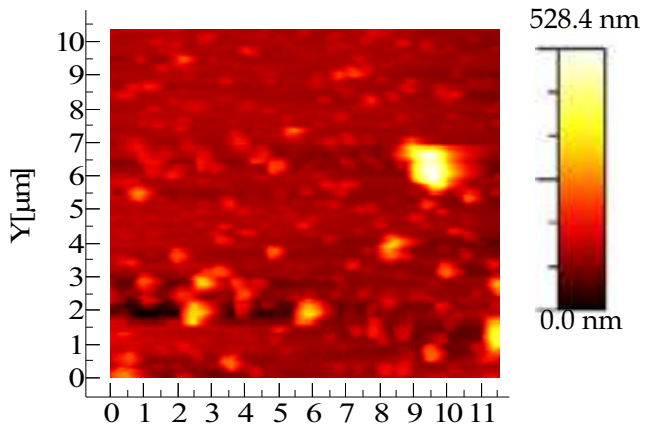

$\mathrm{X}[\mu \mathrm{m}]$

(a)

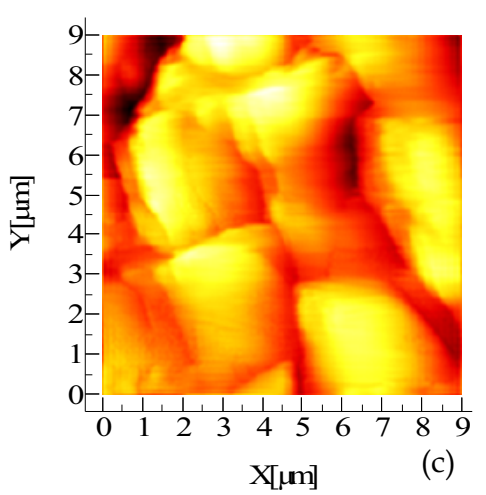

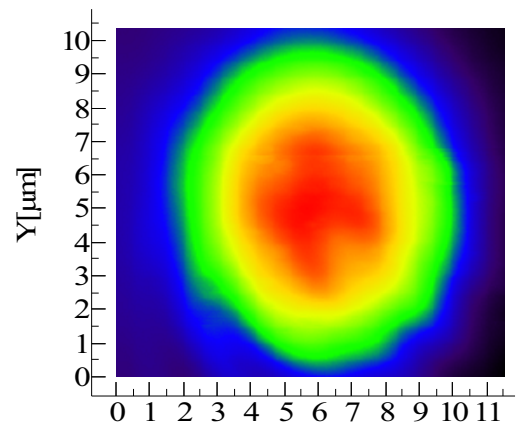

$1.8 \mathrm{~V}$

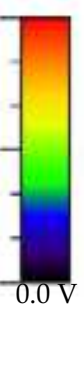

$\mathrm{X}[\mu \mathrm{m}]$

(b)

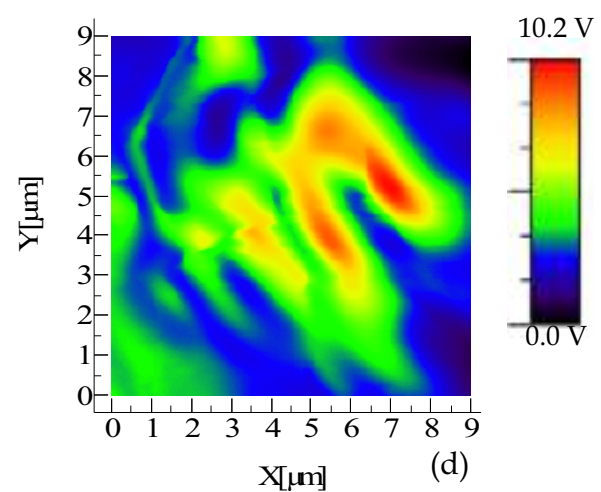

Fig. 9. AFM topographic images (a), (c) and near-field intensity simultaneously collected by the NSOM probe (b), (d) on the sample F and G respectively, prepared using a solution concentration of $0.01 \mathrm{~mol} / \mathrm{l}$, before annealing process.

\subsection{Effect of the post-processing thermal annealing}

In the same work (Buosciolo et al., 2008b), the effect of post processing thermal annealing on surface morphology was also investigated. As matter of fact, two groups of sensors were fabricated by using two different solution concentrations and were characterized before and after the annealing process.

As said in the section 4.4, after the deposition procedure and after the morphological and optical characterization, the prepared samples have been annealed at $500 \pm 5^{\circ} \mathrm{C}$ for 1 hour in order to transform $\mathrm{SnO}_{\mathrm{x}}$ to $\mathrm{SnO}_{2}$ and to clean the films surface from the other dopants, like water or alcohol present in the initial solution. Successively, we were able to compare the sample topography before and after the annealing process since, collecting the emerging near-field from the sample fiber, the accurate definition of the fiber core was possible.

Here we report, for example, the effect of thermal annealing on sample F and G. 
After the thermal treatment sample F topography (see Fig. 10 (a)) is characterized by the presence of several microstructures well separated from each other, whose dimensions are much larger compared to the mean structures dimensions of the $\mathrm{SnO}_{2}$ grain present on the sample surface before annealing. The structures characteristic mean dimensions are: $a=1.136$ $\mu \mathrm{m}, \mathrm{b}=1.347 \mu \mathrm{m}$ and $\mathrm{h}=114 \mathrm{~nm}$. As described before, the presence of such microstructures strongly modify the collected near-field intensity, as it possible to see in Fig. 10 (b).
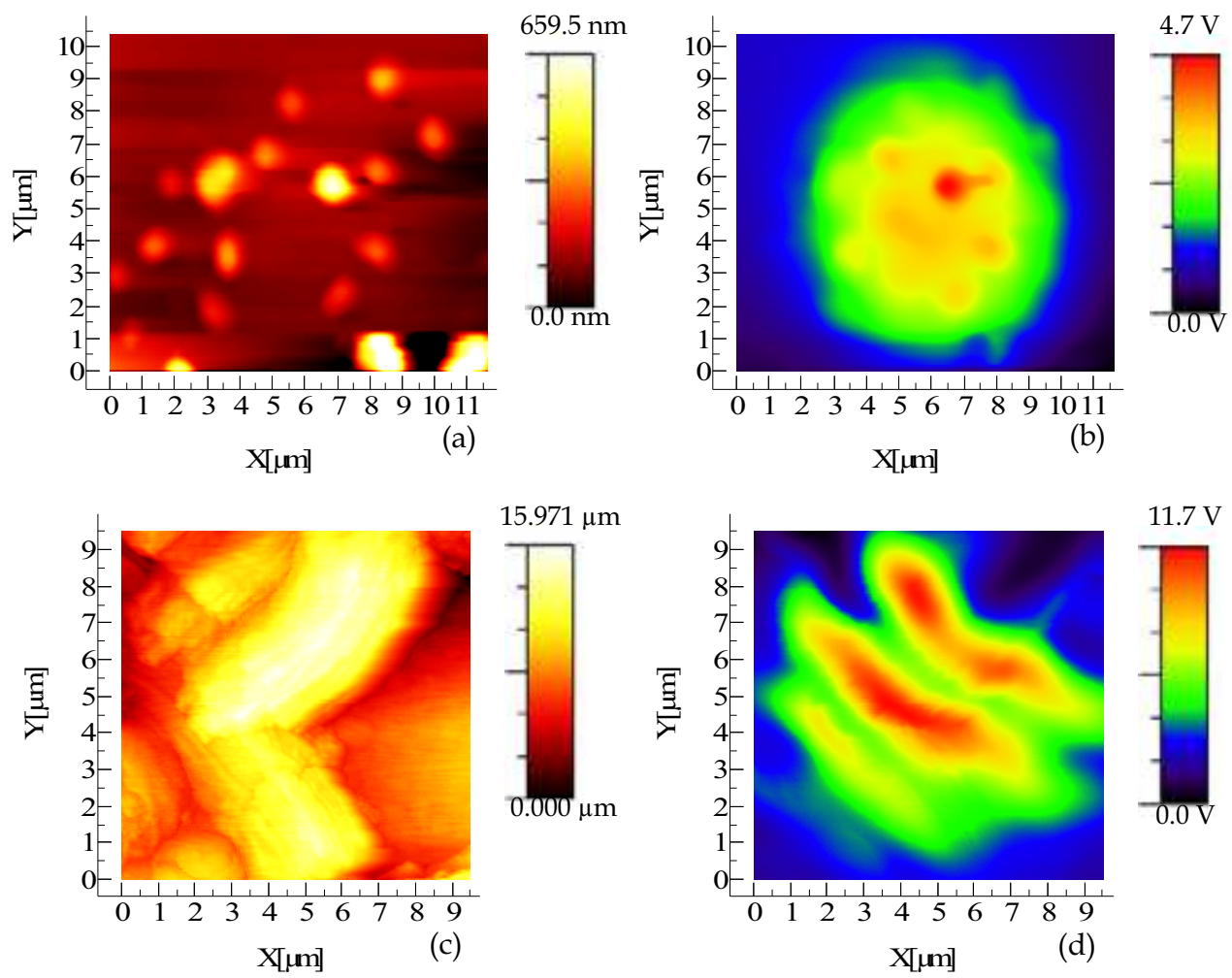

Fig. 10. AFM topographic images (a), (c) and near-field intensity simultaneously collected by the NSOM probe (b), (d) on the sample F and G respectively, after the thermal annealing process.

In fact, the structures spacing is large enough to make it possible an effective light localization in the high refractive index grains. In particular, the prominent effect takes place in correspondence of the central one whose lateral dimension match very well with $\lambda$ : $\mathrm{a}=1.437 \mu \mathrm{m}, \mathrm{b}=1.542 \mu \mathrm{m}$, while the height is $\mathrm{h}=250 \mathrm{~nm}$. We also analyzed the distribution of the heights in the two images reported in Fig. 9 (a) and 10 (a). It was found: an average surface height of $134 \mathrm{~nm}$ and a RMS roughness of $48 \mathrm{~nm}$ before annealing; while an average surface height of $231 \mathrm{~nm}$ and a RMS roughness of $54 \mathrm{~nm}$ after annealing. In this case the RMS roughness before and after the annealing is of the same order of magnitude. 
In Fig. 10 (c) we report the AFM image of the sample G topography and in 10 (d) the nearfield intensity distribution simultaneously collected, after the annealing process. As observable, the surface morphology mainly consists of two elongated structures with mean lateral dimensions (3.6x4.1) $\mu \mathrm{m},(3.3 \times 8.3) \mu \mathrm{m}$ and average height about $8.0 \mu \mathrm{m}$ and $13.5 \mu \mathrm{m}$ respectively. Moreover, it can be seen that the structures are formed by aggregating grains with mean lateral dimensions less than $1 \mu \mathrm{m}$. From Fig. 10 (d), the strong modifications of the emergent near-field profile induced by the aforementioned morphology can be clearly appreciated. Also in this case we report the analysis of the distribution of the heights in the two images reported in Fig. 9 (c) and 10 (c). It was found: an average surface height of 4.431 $\mu \mathrm{m}$ and a RMS roughness of $1.313 \mu \mathrm{m}$ before annealing; while an average surface height of $8.847 \mu \mathrm{m}$ and a RMS roughness of $3.487 \mu \mathrm{m}$ after annealing. In this case the RMS roughness after the annealing became almost three times higher.

As matter of fact, experimental results prove that thermal annealing could be usefully used to increase the crystalline degree of the deposited overlay and mainly to tailor the morphology of the final structure. However, results also show a strong dependence of the effects of the thermal annealing on the initial distribution and size of the particle layers obtained after the deposition stage. This means that the effectiveness of thermal annealing as post processing tool can be really exploited if a controlled particle layer distribution is obtained at the deposition time.

\section{Environmental monitoring application}

In this section, the experimental results demonstrating the high capability of the proposed near-field opto-chemical sensors to be exploited for a wide range of environmental monitoring applications are presented.

In particular, a comparison of the output signal variations of $\mathrm{SnO}_{2}$-based sensors characterized by unperturbed and highly perturbed near-field distributions are reported to demonstrate that the near-field enhancement effect is a key parameter in the optimization of the sensing performances.

The room temperature sensing performances were tested in air, against toluene and xylene vapors, and in water environment against aqueous ammonia.

\subsection{Interrogation scheme}

The optoelectronic architecture exploited for the interrogation of the proposed near-field fiber optic sensors is schematized in Fig. 11. It enables the continuous and real time monitoring of fiber-film reflectance changes occurring as a consequence of analyte interaction with the sensitive tin oxide overlays. It is simple to implement and requires just few widespread commercial and low-cost optoelectronic components while preserving excellent performances.

The sensitive layer was lighted by a pigtailed Superluminescent Light Emitting Diode (SLED) operating in one of the two main telecommunication wavelengths (1310 and 1550 $\mathrm{nm})$. A source controller was used to keep the SLED at a constant temperature and feed it with an input current, which allowed the source to emit an optical power of few $\mathrm{mW}$. This power was split by a $2 \times 2$ in-fiber directional coupler, providing the necessary connections between light source, sensing interface and two InGaAs photodiodes. The first photodiode is for the measurement of the reflected signal: 


$$
V_{\text {signal }}=\mathrm{k}_{1} \cdot \mathrm{Z}_{1} \cdot P_{\text {source }} \cdot \mathrm{R}_{\text {Film }}
$$

where $P_{\text {source }}$ is the power emitted by the source, $\mathrm{k}_{1}$ is a constant which takes account of the power losses due to the coupling factor of the $2 \times 2$ directional coupler and the photodiode responsivity, $Z_{1}$ represents a gain factor introduced by the first photoreceiver device, and $R_{\text {Film }}$ is the fiber/film interface reflectance.

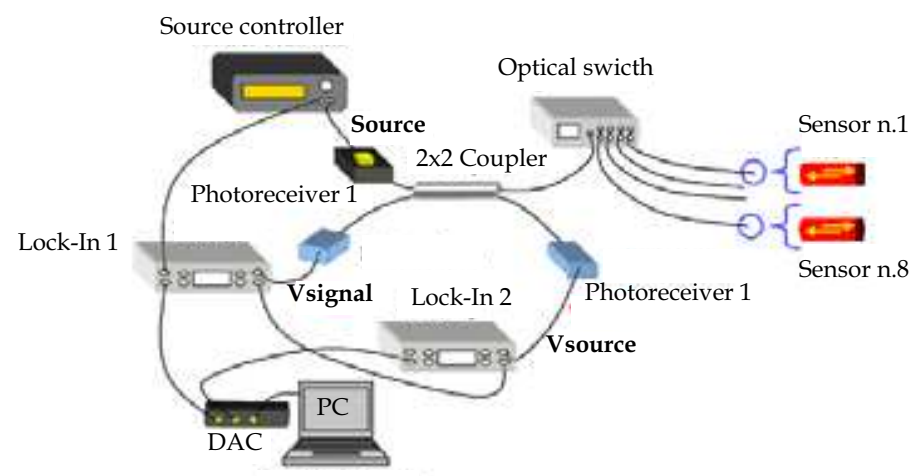

Fig. 11. Schematic illustration of the typical interrogation scneme.

The second arm of the $2 \times 2$ coupler was used to provide a valid intensity monitoring channel for the compensation of the sensor response. As matter of fact, the second photodiode provides a voltage signal directly related to the optical power levels within the optical chain according to:

$$
V_{\text {source }}=\mathrm{k}_{2} \cdot Z_{2} \cdot P_{\text {source }}
$$

where $\mathrm{k}_{2}\left(\mathrm{k}_{2} \neq \mathrm{k}_{1}\right)$ takes into account the losses coming from the connection between source, $2 \times 2$ coupler and photodiode and $Z_{2}\left(Z_{2} \neq Z_{1}\right)$ is a gain factor introduced by the second photoreceiver device. The intensity compensation was obtained by considering the ratio between the voltage signals at the two photo-receivers according to:

$$
\begin{gathered}
\mathrm{I}=\frac{V_{\text {signal }}}{V_{\text {source }}}=\frac{k_{1} \cdot P_{\text {source }} \cdot Z_{1} \cdot \mathrm{R}_{\text {Film }}}{k_{2} \cdot Z_{2} \cdot P_{\text {source }} \cdot}=\alpha \cdot \mathrm{R}_{\text {Film }} \\
\alpha=\frac{k_{1} \cdot Z_{1}}{k_{2} \cdot Z_{2}}
\end{gathered}
$$

where $\alpha$ defined by equation (6), takes into account all the set-up parameters. As evident, the normalized response of the sensor is only sensitive to the change in the reflectance induced by chemical sorption within the sensing overlay and not to the fluctuations of the optical power levels along the whole measurement chain. In the followings, the relative change of the sensor output $\Delta \mathrm{I} / \mathrm{I}_{0}$ has been considered (where $\mathrm{I}_{0}$ is the output signal in the reference or initial condition), which, in turn, corresponds to the relative reflectance change occurring at the fiber-sensitive layer interface $\left(\Delta R / R_{0}\right)$.

Synchronous detection was typically implemented to enhance the system performances, by amplitude modulating the light source at $500 \mathrm{~Hz}$ and retrieving the photodetector voltages by using a dual channel lock-in amplifier. In addition, a Time Division Multiplexing (TDM) 
approach was typically exploited to perform the quasi-simultaneous interrogation of up to eight optical probes by means of a multi-channel fiber optic switch. Finally, the optical data were stored in a notebook controlling the sensing process in LabView software by a NIDAQ card (Penza et al., 2004; Penza et al., 2005; Consales et al., 2007).

\subsection{Detection of volatile organic compounds (VOCs) in air}

In this section, the experimental results on the sensing capability in air environment of two previously characterized $\mathrm{SnO}_{2}$-based probes (respectively sample E and sample G) are reported and compared (Buosciolo et al., 2008b). As observed in the previous sections, the two selected probes were characterized by very dissimilar overlay topographies and by different optical near-field behaviors reported in Fig. 8 (c), 8 (d), 10 (c) and 10 (d) respectively. This enabled a comprehension of the influence of the sensitive layer features on the chemical sensing performance.

The experimental measurements were conducted by adopting the experimental setup reported in Fig. 12. It was used to test the two selected sensors towards ppm concentrations of toluene and xylene vapors, at room temperature. In particular the two transducers were located in a properly designed test chamber characterized by a volume of approximately $1500 \mathrm{ml}$ (Consales et al., 2006 a). The vapors of the analyte under testing were generated by the bubbling method and carried inside the chamber by dry air gas. Dry air was also chosen as reference gas. The total flow rate per exposure was held constant at $2000 \mathrm{ml} / \mathrm{min}$, and controlled by a mass flow-meter driven by a controller-unit communicating with a PC via standard RS-485 serial bus. A thermo-hygrometer was also inserted inside the chamber in order to continuously monitor temperature and humidity variations of the test ambient.

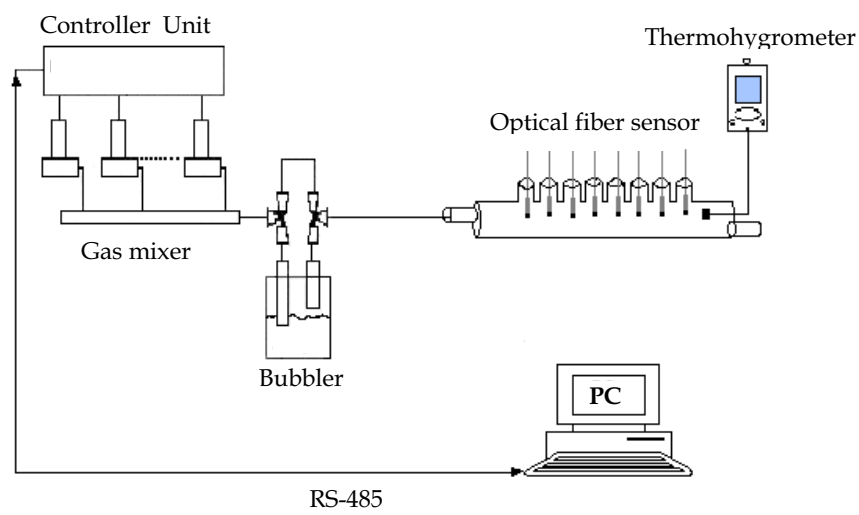

Fig. 12. Schematic representation of the experimental set-up exploited for chemical detection measurements in air, at room temperature.

In Fig. 13, we report the output signal variations $(\Delta \mathrm{I})$ demonstrated by the two near-field opto-chemical sensors $\mathrm{E}$ and $\mathrm{G}$ during the exposure to different pulses of xylene and toluene vapors at room temperature.

The analytes concentration ranged from 25 to $44 \mathrm{ppm}$ and 40 to $83 \mathrm{ppm}$, respectively. The results revealed that significant variations of the overlay reflectance and thus of the sensors output $\Delta \mathrm{I}$ occur as a consequence of the analyte molecules interaction with the $\mathrm{SnO}_{2}$ particle 
layer, demonstrating the surprising capability of the tested metal oxide based transducers of detecting few tens of ppm of the chosen chemicals at room temperature. This effect is especially evident for sample $G$ which, as previously described, turned out to be characterized by the most pronounced modification of the optical near-field transmitted through the fiber coating. As matter of fact the signal changes in the case of the probe $G$ are approximately of two orders of magnitude higher than the ones obtained for the counterpart sensor E.
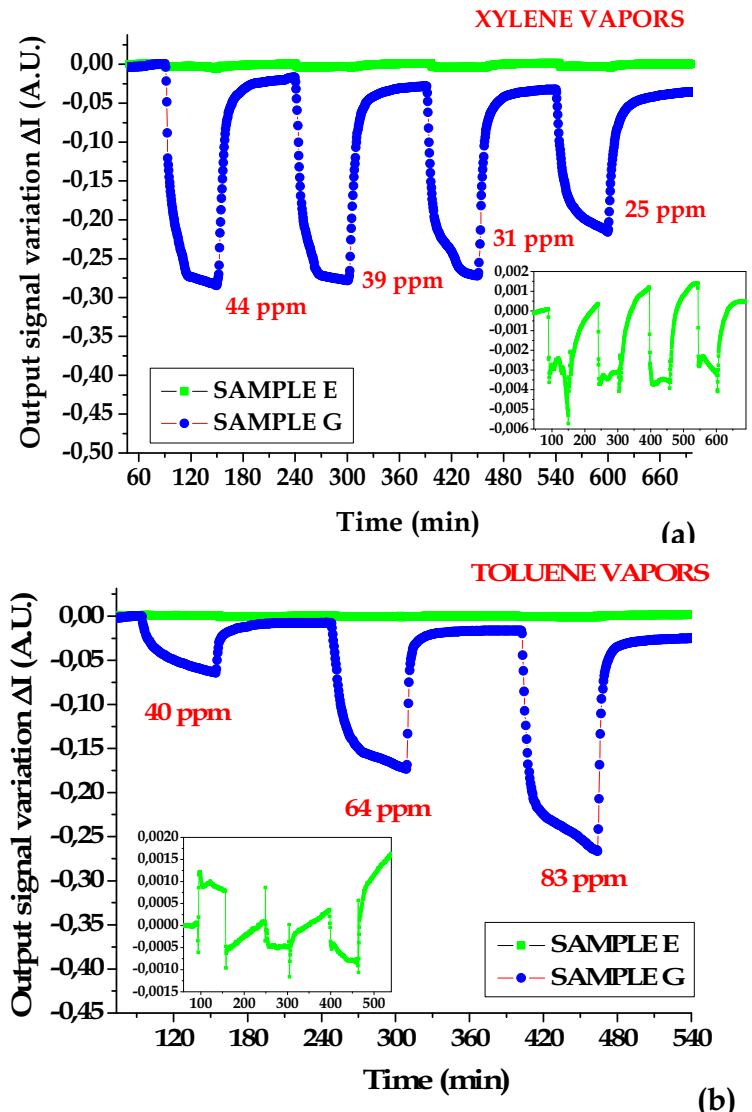

Fig. 13. Output signal variations $(\Delta \mathrm{I})$ occurred to the near-field opto-chemical sensors $\mathrm{E}$ and $G$ upon the exposure to different concentration pulses of xylene (a) and toluene (b) vapors at room temperature. The insets report the responses of sensor $\mathrm{E}$.

Very dissimilar response dynamics were also observed for the two sensors, with the sample E characterized by a faster response. This could be attributed to a different interaction with the selected chemical. Sample E also revealed to be less reliable than sample $G$, as demonstrated by the opposite in sign responses it exhibited upon the exposure to different toluene pulses (see inset in Fig. 13 (b)). In particular, with regards sample G, excellent sensitivities (calculated as output signal variation upon concentration unit) of $6.6 \cdot 10^{-3} \mathrm{ppm}^{-1}$ 
and 3.0.10-3 $\mathrm{ppm}^{-1}$ for xylene and toluene vapors, respectively, that lead to sub-ppm limits of detection, good and fast reversibility features as well as response times of approximately 25 and 35 minutes, respectively were obtained.

The excellent sensing capabilities of sensors $G$ with respect to sample E can be explained by the fact that, optical probes coated by sensitive overlays with very rough morphologies are characterized by enhanced detection performance with respect to those based on almost flat $\mathrm{SnO}_{2}$ overlays. As matter of fact, when the $\mathrm{SnO}_{2}$ overlay surface exhibits microstructures able to strongly perturb the emergent optical field profile producing its local enhancement, the interaction of the field with the analyte occurs mainly on its surface by means of the evanescent part of the field. This is able to improve the performance of fiber optic sensors based on metal oxides since they rely mainly on surface interactions.

In conclusion, by properly tailoring the deposition parameters, different morphologies of the tin dioxide coatings can be obtained in order to suite the particular application. This particular feature allowed by the ESP method, together with the possibility to tailor the sensitivity and dynamics characteristics of the $\mathrm{SnO}_{2}$-based SOF probes could be very useful in chemical sensing applications. In fact, the correlation between data collected from sensors coated by layers of the same materials exhibiting highly dissimilar characteristics could enhance the features extraction from a hybrid system by means of pattern recognition methods. Consequentially, this could allow to overcome the typical low-selectivity of the exploited sensitive materials towards a given chemical specie.

\subsection{Detection of ammonia molecules in water}

In this section, the experimental results on the sensing capability in water environment of two previously characterized $\mathrm{SnO}_{2}$-based probes (respectively sample A and sample $\mathrm{B}$ ) are reported and compared (Cusano et al., 2006; Consales et al., 2006b) . As observed in the previous sections, the two selected probes were characterized by very dissimilar overlay topographies and by different optical near-field behaviors reported in Fig. 4 (a), 4 (b), 5(a) and $5(b)$, respectively.

To this aim, the optoelectronic transducers in the reflectometric configuration have been inserted in a Pyrex beaker containing pure water, as reported in Fig. 14 (Pisco et al., 2005; Pisco et al., 2006).

The presence within the test ambient of ammonia molecules was promoted by its injection inside the beaker. The volume of an aqueous solution of ammonia was chosen, each time, in order to obtain the desired analyte concentration. In addition, after each ammonia exposure, the capabilities of the proposed SOF sensors to recover the initial steady state level were tested by restoring the initial condition of pure water. To this aim, pure water was continuously injected in the test chamber, while the contaminated water, previously present in it, contemporarily stilled out.

The two near-field opto-chemical sensors A and B were exposed to different concentration of ammonia in water ranging from $1 \mathrm{ppm}$ to $12 \mathrm{ppm}$. In Fig. 15 are reported the results obtained from several testing performed on the probe sample A over a time interval of 1 month (Cusano et al., 2006). 
Beaker with

pure water

Sensor probe

Test

beaker

Exaust

Fig. 14. Schematic view of the experimental set-up exploited for the in water chemical detection measurements.

In particular, Fig. 15 reveals that very different behaviors in the sensor response occur in the same test conditions. The change direction and amplitude as well as the response dynamics are strongly dissimilar during the testing carried out in different days using the same testing features. On the contrary, the results obtained by exposing the probe sample B to ammonia with repeated concentrations of 1 ppm and 5 ppm (reported in Fig. 16 (a)) were highly satisfactory.
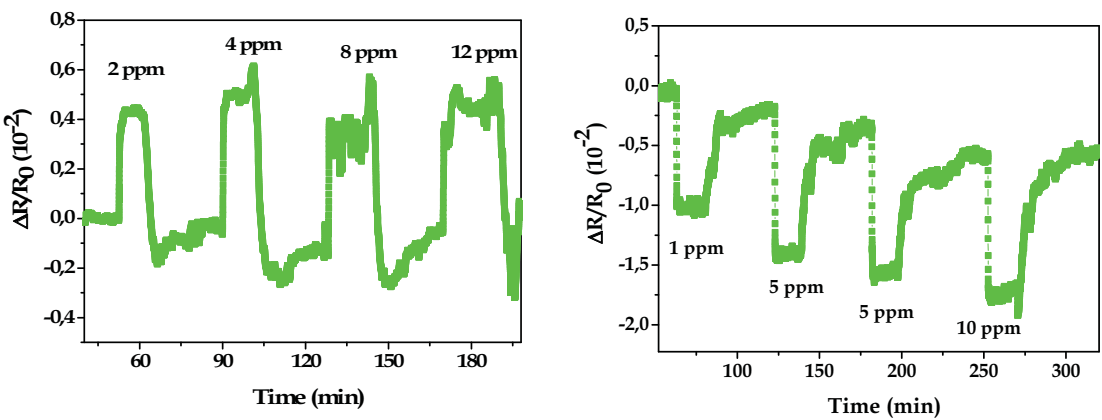

Fig. 15. Optical responses obtained with the probe sample A from several ammonia adsorption testing in water at room temperature.

In fact a good sensitivity was obtained (the resolution of the sensor was estimated to be approximately $80 \mathrm{ppb}$ ), together with fast response and recovery times (response time of 5 and $7 \mathrm{~min}$ and recovery times of 12 and $15 \mathrm{~min}$ were calculated for 1 and $5 \mathrm{ppm}$, respectively) as well as a good repeatability of the sensor response, as demonstrated by a repeatability error lower than the sensor resolution. The slight drift which can be observed on the steady state level of the sensor response is due to the thermal changes $\Delta T$ (also reported in Fig. 16 (a)) occurred inside the test chamber, since it is not perfectly thermostated. 

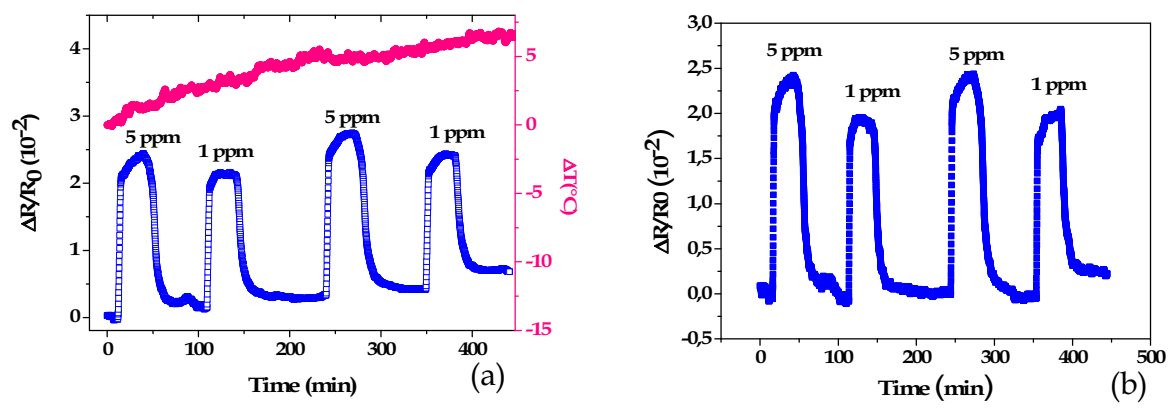

Fig. 16. Optical response obtained with the probe Sensor B in correspondence of four injections of ammonia, with repeated concentrations of $1 \mathrm{ppm}$ and $5 \mathrm{ppm}$, and temperature changes $\Delta \mathrm{T}$ occurred during the same testing (a), and sensor response after the temperature compensation procedure (b).

However this drift was been easily compensated by a proper compensation procedures employing an optical Fiber Bragg Grating temperature sensor, which was inserted inside the chamber or even integrated within the sensing fibers (Cusano et al., 2004). This is evident from the results shown in Fig. 16 (b), the response of the probe sample B after the compensation procedure has been reported, and shows that the drift previously observable on the signal baseline is totally compensated. In addition the probe sample B, differently from what happened with the probe sample A, demonstrated to be sufficiently reliable, since its stability in water was observed over the whole testing period of five weeks.

All the results obtained from the experimental measurements confirm the surprising potentiality of the proposed ammonia sensor and its feasibility to be used for water quality monitoring applications. Moreover, similarly to what happens for the detection in air, also in the case of water monitoring the $\mathrm{SnO}_{2}$ layers topography and hence the near-field profile, strongly influences the sensor response, allowing to appropriately tailor the film features in order to obtain the best performances.

\section{Conclusion}

In conclusion, in this work, we demonstrated a novel technological platform for optochemical sensing employing particle layers of tin dioxide at wavelength scale with performances enhanced by the near-fields effects due to the confined domains of the layer. For the integration of the chemo sensitive layer onto fiber optic substrates, the ESP deposition technique has been selected providing a good balance between easily implementation and particle size and distribution control by acting on the processing parameters. In order to understand the influence of the film morphology on the optical field emerging from the film, AFM-SNOM characterization has been carried out revealing that layers with surface features of the order of the radiation wavelength demonstrated their capability to generate and to modify the optical near-field emerging from the overlay.

From this phenomenon arise the excellent sensing performances of the $\mathrm{SnO}_{2}$-based transducers, as most of the interaction between the sensing coatings and analyte molecules 
occurs on the layer surface by means of the evanescent wave, strongly enhanced by nearfield effects. Also, we showed how by acting on the deposition parameters and by using post processing stages (such as thermal annealing), it is possible to modify the morphology of the sensitive overlay in terms of grain size, spacing and distribution.

It is important to note that significant margins exist for the improvements of this class of sensors especially after completing the investigation on the influence of process and post process variables (electric field, concentration, volume, deposition time, substrate deposition temperature) on the overlay morphology.

Also, an important step should be devoted to the identification of the correspondence morphology-near-field effects and its consequences on the sensing performance of the final device. Finally, it is important to remark that high sensitivity opto-chemical sensors employable in both air and aqueous environments with sub-ppm resolution have been demonstrated by using a simple and low cost fabrication method, also usable with other multifunction materials.

\section{References}

Ansary, S. G.; Gosavi, S. W.; Gangal, S. A.; Karekar, R. N.; Aiyer, R. C. (1997). Characterization of $\mathrm{SnO}_{2}$-based $\mathrm{H}_{2}$ gas sensors fabricated by different deposition techniques. Journal of Materials Science: Materials in Electronics. Vol. 8, No. 1, (1997), 23-27.

Arnold, M. S.; Avouris, P.; Pan, Z. W.; Wang, Z. L. (2003). Field-effect transistors based on single semiconducting oxide nanobelts. Journal of Physical Chemistry B, Vol. 107, (2003), 659-663.

Baratto, C.; Comini, E.; Faglia, G.; Sberveglieri, G.; Zha, M.; Zappettini, A. (2005). Sensors and Actuators B, Vol. 109 (2005) 2-6.

Barsan, N.; Schweizer-Berberich, M.; Gopel, W. (1999). Fundamental and practical aspects in the design of nanoscaled $\mathrm{SnO}_{2}$ gas sensors: a status report. Fresenius' Journal of Analytical Chemistry, Vol. 365, (1999), 287-304.

Becker, T.; Ahlers, S.; Bosh-v.Braunmuhl, C.; Muller, G., Kiesewetter, O. (2001). Gas sensing properties of thin- and thick-film tin-oxide materials. Sensors and Actuators B, Vol. 77, (2001), 55-61.

Brattain, W.H.; Bardeen, J. (1952). Surface properties of germanium. Bell System Technical Journal, Vol. 32 (1952) 1.

Buosciolo, A.; Consales, M.; Pisco, M.; Cusano A.; Giordano, M. (2008 b). Fiber Optic NearField Chemical Sensors Based on Wavelength Scale Tin Dioxide Particle Layers. Journal of Lightwave Technology, Vol. 26, No. 20, (October 2008), 3468-3475.

Buosciolo, A.; Consales, M.; Pisco, M.; Cusano, A.; Giordano, M. (2008 a). Near-Field Fiber Optic Chemo Sensors. Proceedings of the First Mediterranean Photonics Conference, pp. 302-304, Ischia, Italy,June 2008.

Buosciolo, A.; Pilla, P.; Consales, M.; Pisco, M.; Cutolo, A.; Giordano, M.; Cusano, A. (2006). Near Field Behaviour of $\mathrm{SnO}_{2}$ Particle-layers Deposited on Optical Fibers: New Perspectives for Sensing Applications. Technical Digest of 18th International Optical Fiber Sensors Conference, Paper TuE77,Cancun, Mexico, October 2006. 
Chen, X. H. and Moskovits, M. (2007). Observing catalysis through the agency of the participating electrons: Surface-chemistry-induced current changes in a tin oxide nanowire decorated with silver. Nano Letters, Vol. 7, (2007), 807-812.

Chen, P.; Shen, G.; Zhou, C. (2008). Chemical Sensors and Electronic Noses Based on 1-D Metal Oxide Nanostructures. IEEE Transactions on Nanotechnology, Vol. 7, No.6, (2008), 668-682.

Cirera, A.; Cabot, A.; Cornet, A. ; Morante, J.R. (2001). $\mathrm{CO} \mathrm{CH}_{4}$ selectivity enhancement by in situ Pd-catalysed microwave $\mathrm{SnO}_{2}$ nanoparticles for gas detectors using active filter. Sensors and Actuators B, Vol. 78, (2001), 151- 160.

Comini, E.; Faglia, G.; Sberveglieri, G.; Pan, Z. W.; Wang, Z. L. (2002). Stable and highly sensitive gas sensors based on semiconducting oxide nanobelts. Applied Physics Letters, Vol. 81, (2002), 1869-1871.

Comini, E. (2008). Metal oxide nano-crystal for gas sensing. Analytica Acta, Vol. 568, (2008), 28-40.

Comini, E.; Faglia, G.; Sberveglieri G. UV light activation of tin oxide thin films for $\mathrm{NO}_{2}$ sensing at low temperatures. Sensors and Actuators B, Vol. 78, No. 1-3, (August 2001), 73-77.

Consales, M.; Campopiano, S.; Cutolo, A.; Penza, M.; Aversa, P.; Cassano, G.; Giordano, M.; Cusano, A. (2006 a). Carbon nanotubes thin films fiber optic and acoustic VOCs sensors: Performances analysis. Sensors and Actuators B, Vol. 118, No. 1-2, (October 2006), 232-242.

Consales, M. ; Cutolo, A. ; Penza, M.; Aversa, P.; Cassano, G.; Giordano, M.; Cusano, A. (2007 b). Carbon Nanotubes Coated Acoustic and Optical VOCs Sensors: Towards the Tailoring of the Sensing Performances. IEEE Transactions on Nanotechnology, Vol. 6, No. 6, (November 2007), 601-612.

Consales, M.; Pisco, M.; Buosciolo, A.; Viter, R.; Smyntyna, V.; Cutolo, A.; Giordano M.; Cusano, A. (2007 a). High Sensitivity Near-Field Opto-Chemical Sensors Based on $\mathrm{SnO}_{2}$ Particles Layers. Proceedings of the Third European Workshop on Optical Fibre Sensors, Vol. 6619, pp. 66191G1-G4, Naples, Italy, July 2007.

Consales, M.; Pisco, M.; Pilla, P. ; Cusano, A.; Buosciolo, A.; Giordano, M.; Viter, R.; Smyntyna, V. (2006 b). Influence of Layers Morphology on the Sensitivity of $\mathrm{SnO}_{2^{-}}$ Based Optical Fiber Sensors. Proceedings of 5th IEEE Conference on Sensors, pp. 581584, Daegu, Korea, October 2006.

Cui, Y.; Wei, Q. Q.; Park, H. K.; Lieber, C. M. (2001). Nanowire Nanosensors for Highly Sensitive and Selective Detection of Biological and Chemical Species. Science, Vol. 293, (2001), 1289-1292.

Cusano, A.; Consales, M.; Pisco, M.; Pilla, P.; Cutolo, A.; Buosciolo, A.; Viter, R. ; Smyntyna V.; Giordano, M. (2006). Opto-chemical sensor for water monitoring based on $\mathrm{SnO}_{2}$ particle layer deposited onto optical fibers by the electrospray pyrolysis method. Applied Physics Letters, Vol. 89, (September 2006) , 111103 1-3.

Cusano, A.; Pilla, P.; Consales, M.; Pisco, M. ; Cutolo, A.; Buosciolo A.; Giordano, M. (2007). Near field behavior of $\mathrm{SnO}_{2}$ particle-layer deposited on standard optical fiber by electrostatic spray pyrolysis method. Optics Express, Vol. 15, No. 8, (April 2007), 5136-5146. 
Cusano, A.; Persiano, G.V.; Russo, M.; Giordano, M. (2004). Novel optoelectronic sensing system for thin polymer films glass transition investigation. IEEE Sensors Journal, Vol. 4, No. 6, (December 2004), 837- 844

Delpha, C.; Lumbreras, M.; Siadat, M. (2004). Discrimination and identification of a refrigerant gas in a humidity controlled atmosphere containing or not carbon dioxide: application to the electronic nose. Sensors and Actuators B, Vol. 98, (2004), 46-53.

Eranna, G.; Joshi, B. C.; Runthala, D. P.; Gupta, R. P. (2004). Oxide Materials for Development of Integrated Gas Sensors - A Comprehensive Review. Critical Reviews in Solid State and Materials Sciences, Vol. 29, No. 3, (2004), 111-188.

Faglia, G.; Baratto, C.; Sberveglieri, G.; Zha, M.; Zappettini, A. (2005). Adsorption effects of $\mathrm{NO}_{2}$ at ppm level on visible photoluminescence response of $\mathrm{SnO}_{2}$ nanobelt. Applied Physics Letters, Vol. 86, (2005), 011923.

Fort, A.; Gregorkiewitz, M.; Machetti, N.; Rocchi, S.; Serrano, B.; Tondi, L.; Ulivieri, N.; Vignoli, V.; Faglia G.; Comini E. (2002). Selectivity enhancement of $\mathrm{SnO}_{2}$ sensors by means of operating temperature modulation. Thin Solid Films, Vol. 418, No. 1, (October 2002), 2-8.

Gardner, J.W.; Hines, E.L.; Tang, H.C. (1992). Detection of vapours and odours from a multisensor array using pattern-recognition techniques. Part II. Artificial neural networks, Sensors and Actuators B, Vol. 9, (1992), 9-15.

Ghimbeu, C.M.; Van Landschoot, R.C.; Schoonman, J.; and Lumbreras, M. (2007) Preparation and characterization of $\mathrm{SnO}_{2}$ and $\mathrm{Cu}$-doped $\mathrm{SnO}_{2}$ thin films using electrostatic spray deposition (ESD). Journal of the European Ceramic Society, Vol. 27, No. 1, (2007), 207-213.

Gourari, H.; Lumbreras, M.; Landschoot, R.V. ; Schoonman, J. (1998). Elaboration and characterization of $\mathrm{SnO}_{2}-\mathrm{Mn}_{2} \mathrm{O}_{3}$ thin layers prepared by electrostatic spray deposition. Sensors and Actuators B, Vol. 47, (April 1998), 189-193.

Gourari, H.; Lumbreras, M.; Landschoot, R.V. ; Schoonman, J. (1999). Electrode nature effects on stannic oxide type layers prepared by electrostatic spray deposition. Sensors and Actuators B, 58 Vol. 1-3, (September 1999) 365-369.

Heilig, A.; Barsan, N.; Weimar, U.; Gopel, W. (1999). Selectivity enhancement of $\mathrm{SnO}_{2}$ gas sensors: simultaneous monitoring of resistances and temperatures. Sensors and Actuators B, Vol. 58, (1999), 302-309.

Helwig, A.; Muller, G.; Sberveglieri, G.; Faglia, G. (2007). Gas response times of nano-scale $\mathrm{SnO}_{2}$ gas sensors as determined by the moving gas outlet technique. Sensors and Actuators B, Vol. 126, (2007), 174-180.

Higashiyama, Y.; Tanaka, S.; Sugimoto, T.; Asano, K.; (1999). Size distribution of the charged droplets in an axisymmetric shower. Journal of Electrostatics, Vol. 47, (1999), 183-195.

Hong, H.K.; Kwon, C.H.; Kim, S.R.; Yun, D.H.; Lee, K.; Sung, Y.K. (2000). Portable electronic nose system with gas sensor array and artificial neural network. Sensors and Actuators B, Vol. 66, (2000), 49-52.

Ihokura, K. (1981). Tin oxide gas sensor for deoxydising gases. New Matter. New Processes in Electrochemical Technology, Vol. 143 (1981).

Ihokura, K.; Watson, J. (1994). The stannic oxide gas sensor: principles and applications. CRC Press, Boca Raton, ISBN 0849326044 (1994). 
Ivanov, P.; Llobet, E.; Vilanova, X.; Brezmes, J.; Hubalek, J.; Correig, X. (2004). Development of high sensitivity ethanol gas sensors based on Pt-doped $\mathrm{SnO}_{2}$ surfaces. Sensors and Actuators B, Vol. 99, (2004), 201-206.

Kolmakov, A.; Klenov, D. O.; Lilach, Y.; Stemmer, S.; Moskovits, M. (2005). Enhanced gas sensing by individual $\mathrm{SnO}_{2}$ nanowires and nanobelts functionalized with $\mathrm{Pd}$ catalyst particles. Nano Letters, Vol. 5, (2005), 667-673.

Law, M.; Kind, H.; Messer, B.; Kim, F.; Yang, P. D. (2002). Photochemical sensing of $\mathrm{NO}_{2}$ with $\mathrm{SnO}_{2}$ nanoribbon nanosensors at room temperature. Angewandte ChemieInternational Edition, Vol. 41, (2002), 2405-2408.

Lee, D.S.; Jung, J.K.; Lim, J.W.; Huh, J.S.; Lee, D.D. (2001). Recognition of volatile organic compounds using $\mathrm{SnO}_{2}$ sensor array and pattern recognition analysis. Sensors and Actuators B, Vol. 77, (2001), 228-236.

Lezec, H. J.; Thio, T. (2004). Diffracted evanescent wave model for enhanced and suppressed optical transmission through subwavelength hole arrays. Optics Express, Vol. 12, (2004), 3629-3651.

Li, C.; Zhang, D. H.; Liu, X. ,L.; Han, S.; Tang, T.; Han, J.; Zhou, C. W. (2003). $\mathrm{In}_{2} \mathrm{O}_{3}$ nanowires as chemical sensors. Applied Physics Letters, Vol. 82, (2003), 1613-1615.

Llobet, E.; Brezmes, J.; Vilanova, X; Sueiras, J.E.; Correig, X. (1997). Qualitative and quantitative analysis of volatile organic compounds using transient and steadystate responses of a thick-film oxide gas sensor array. Sensors Actuators B, Vol. 41 (1997) 13-21.

Lundstrom, I. (1996). Approaches and mechanisms to solid state based sensing. Sensors and Actuators B, Vol. 35-36, (1996), 11-19.

Maffeis, T. G. G.; Owen, G. T.; Penny, M.W.; Starke, T. K. H; Clark, S. A.; Ferkel, H.; Wilks, S. P. (2002). Nano-crystalline $\mathrm{SnO}_{2}$ gas sensor response to $\mathrm{O}_{2}$ and $\mathrm{CH}_{4}$ at elevated temperature investigated by XPS. Surface Science, Vol. 520, (2002), 29-34.

Matsui, Y.; Mitsuhashi , M.; Goto, Y. (2003). Early stage of tin oxide film growth in chemical vapor deposition. Surface and Coatings Technology, Vol. 169, (2003), 549-552.

Matsushima, Y.; Nemoto, Y.; Yamazaki, T.; Maeda, K.; Suzuki, T. (2003). Fabrication of $\mathrm{SnO}_{2}$ particle-layer on the glass substrate using electrospray pyrolysis method and the gas sensitivity for $\mathrm{H}_{2}$. Sensors and Actuators B, Vol. 96, (May 2003) 133-138.

Meyer, E.; Hug, H. J.; Bennewitz R. (2003). Scanning probe microscopy: the lab on a tip. Springer, ISBN 3540431802. Berlin.

Ngo, K.A.; Lauque, P.; Aguir, K.(2006). Identification of toxic gases using steady state and transient responses of gas sensor array. Sensor Materials, Vol. 18 (2006) 251-260.

Pan, Z.W.; Dai Z.R.; Wang, Z.L. (2001). Nanobelts of semiconducting oxides. Science, Vol. 291, (2001), 1947-1949.

Panchapakesan, B.; Cavicchi, R.; Semancik, S.; DeVoe, D. L. (2006). Sensitivity, selectivity and stability of tin oxide nanostructures on large area arrays of microhotplates. Nanotechnology, Vol. 17, (2006), 415-425.

Patil, P. S. (1999). Versatility of chemical spray pyrolysis technique. Materials Chemistry and Physics, Vol. 59, (February 1999), 185-198.

Patil, P. S.; Kawar, R. K.; Seth, T.; Amalnerkar D. P.; Chigare, P.S. (2003). Effect of substrate temperature on structural, electrical and optical properties of sprayed tin dioxide $\left(\mathrm{SnO}_{2}\right)$ thin films. Ceramics International, Vol.20, No. 7, (2003), 725-734. 
Penza, M.; Cassano, G.; Aversa, P.; Antolini, F.; Cusano, A.; Cutolo, A.; Giordano, M.; Nicolais, L. (2004). Alcohol detection using carbon nanotubes acoustic and optical sensors. Applied Physics Letters, Vol. 85, No. 12, (September 2004), 2379 1-3.

Penza, M.; Cassano, G.; Aversa, P.; Antolini, F.; Cusano, Consales, M.; Giordano, M.; Nicolais, L. (2005). Carbon nanotubes-coated multi-transducing sensors for VOCs detection. Sensors and Actuators B, Vol. 111-112, (November 2005), 171-180.

Perednis D.; Gauckler L. J. (2005). Thin film deposition using spray pyrolysis. Journal of Electroceramics, Vol. 14, (2005), 103-111.

Pink, H.; Treitinger, L.; Vité,L. (1980). Preparation of Fast Detecting $\mathrm{SnO}_{2}$ Gas Sensors. Japanese Journal of Applied Physics, Vol. 19, (1980), 513-517.

Pisco, M.; Consales, M.; Campopiano, S.; Viter, R.; Smyntyna, V.; Giordano M.; Cusano A. (2006). A novel opto-chemical sensor based on $\mathrm{SnO}_{2}$ sensitive thin film for ppm ammonia detection in liquid environment. Journal of Lightwave Technology, Vol. 24, N. 12, (December 2006), 5000-5007.

Pisco, M.; Consales, M.; Viter, R.; Smyntyna, V.; Campopiano, S.; Giordano, M.; Cusano, A.; Cutolo, A. (2005). Novel $\mathrm{SnO}_{2}$ based optical sensor for detecting low ammonia concentration in water at room temperatures. Semiconductor Physics, Quantum Electronics \& Optoelectronics, Vol. 8, No. 1, (2005) 95-99.

Qian, L. H.; Wang, K.; Li, Y.; Fang, H. T.; Lu, Q. H.; Ma X. L. (2006). CO sensor based on Audecorated $\mathrm{SnO}_{2}$ nanobelt. Materials Chemistry and Physics, Vol. 100, (2006), 82-84.

Ramamoorthy, R.; Kennedy, M. K.; Nienhaus, H.; Lorke, A.; Kruis, F. E.; Fissan, H. (2003). Surface oxidation of monodisperse $\mathrm{SnO}_{\mathrm{x}}$ nanoparticles. Sensors and Actuators B, Vol. 88, (2003) 281-285.

Rumyantsevaa, M. N.; Kovalenkoa, V. V.; Gaskova, A. M.; Pagnierb, T. (2008). Metal-Oxide Based Nanocomposites as Materials for Gas Sensors. Russian Journal of General Chemistry, Vol. 78, No. 5, (2008), 1081-1092.

Sberveglieri, G. (1995). Recent developments in semiconducting thin-film gas sensors. Sensors and Actuators B, Vol. 23, (1995) 103-109.

Schweizer-Berberich, M.; Zdralek, M.; Weimar, U.; Gopel, W.; Vidal, T.; Martinez, D.; PeyreLavigne, A.; (2000). Pulsed mode of operation and artificial neural networks evaluation for improving the $\mathrm{CO}$ selectivity of $\mathrm{SnO}_{2}$ gas sensors. Sensors and Actuators B, Vol. 65, (2000), 91-93.

Seiyama, T.; Kato, A.; Fujushi, K.; Nagatani, M. (1962). A new detector for gaseous components using semiconductive thin films. Analytical Chemistry, Vol. 34 , (1962), $1502 f$.

Setaro, A.; Bismuto A.; Lettieri S.; Maddalena P.; Comini E.; Bianchi S.; Baratto C.; Sberveglieri G. (2008). Optical sensing of $\mathrm{NO}_{2}$ in tin oxide nanowires at sub-ppm level. Sensors and Actuators B, Vol. 130, (2008), 391-395.

Sysoev, V. V.; Button, B. K.; Wepsoec, K.; Dmitriev, S.; Kolmakov, A. (2006). Toward the nanoscopic "electronic nose": Hydrogen vs. carbon monoxide discrimination with an array of individual metal oxide nano- and mesowire sensors. Nano Letters, Vol. 6, (2006), 1584-1588.

Szklarski, Z. (1989). Thin oxide films as gas sensors. Thin Solid Films, Vol. 174, (1989), 269275.

Taguchi, N. (1962). Japanese Patent, S45-38200, (1962). 
Wan, Q.; Huang, J.; Xie, Z.; Wang, T.; Dattoli, E. N.; Lu, W. (2008). Branched $\mathrm{SnO}_{2}$ nanowires on metallic nanowire backbones for ethanol sensors application. Applied Physics Letters, Vol. 92, (2008), 102101-102103.

Watson, J. (1984). The tin oxide gas sensor and its applications. Sensors and Actuators B, Vol. 5, (1984), 29-42.

Watsont, J.; Ihokura K.; Colest, G.S.V. (1993). The tin dioxide gas sensor. Measurement Science and Technology, Vol. 4 , (1993), 711-719.

Yamazoe, N.; Kurokawa, Y.; Seiyama T. (1983). Effects of additives on semiconductor gas sensors. Sensors and Actuators B, Vol. 4 , 283-289.

Yamazoe, N. (1991). New approaches for improving semiconductor gas sensors. Sensors and Actuators B, Vol. 5, (1991), 7-19.

Yu, C.; Hao, Q.; Saha S.; Shi, L.; Kong, X.; Wang, Z. L. (2005). Integration of metal oxide nanobelts with microsystems for nerve agent detection. Applied Physics Letters, Vol. 86, (2005), 063101-063103.

Zaouk, D.; Zaatar, Y.; Khoury, A.; Llinares, C.; Charles, J.-P.; Bechara, J. (2000). Electrical and optical properties of pyrolytically electrostatic sprayed fluorine-doped tin-oxide: dependence on substrate-temperature and substrate-nozzle distance. Journal of Applied Physics, Vol. 87, No. 10, (May 2000) 7539-7543.

Zhang, Y.; Kolmakov, A.; Chretien, S.; Metiu H.; Moskovitz, M. (2004). Control of Catalytic Reactions at the Surface of a Metal Oxide Nanowire by Manipulating Electron Density Inside It. Nano Letters, Vol. 4, No. 3, (2004), 403-407. 


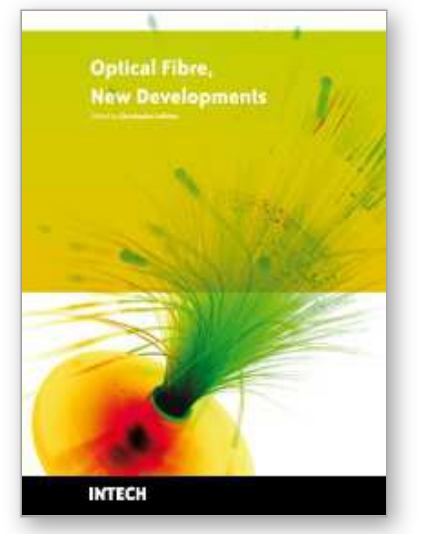

\section{Optical Fiber New Developments}

Edited by Christophe Lethien

ISBN 978-953-7619-50-3

Hard cover, 586 pages

Publisher InTech

Published online 01, December, 2009

Published in print edition December, 2009

The optical fibre technology is one of the hop topics developed in the beginning of the 21 th century and could substantially benefit applications dealing with lighting, sensing and communication systems. Many improvements have been made in the past years to reduce the fibre attenuation and to improve the fibre performance. Nowadays, new applications have been developed over the scientific community and this book fits this paradigm. It summarizes the current status of know-how in optical fibre applications and represents a further source of information dealing with two main topics: the development of fibre optics sensors, and the application of optical fibre for telecommunication systems.

\section{How to reference}

In order to correctly reference this scholarly work, feel free to copy and paste the following:

Antonietta Buosciolo, Marco Consales, Marco Pisco, Michele Giordano and Andrea Cusano (2009). Near-Field Opto-Chemical Sensors, Optical Fiber New Developments, Christophe Lethien (Ed.), ISBN: 978-953-7619-503, InTech, Available from: http://www.intechopen.com/books/optical-fiber-new-developments/near-field-optochemical-sensors

\section{INTECH}

open science | open minds

\section{InTech Europe}

University Campus STeP Ri

Slavka Krautzeka 83/A

51000 Rijeka, Croatia

Phone: +385 (51) 770447

Fax: +385 (51) 686166

www.intechopen.com

\section{InTech China}

Unit 405, Office Block, Hotel Equatorial Shanghai

No.65, Yan An Road (West), Shanghai, 200040, China

中国上海市延安西路65号上海国际贵都大饭店办公楼 405 单元

Phone: +86-21-62489820

Fax: $+86-21-62489821$ 
(C) 2009 The Author(s). Licensee IntechOpen. This chapter is distributed under the terms of the Creative Commons Attribution-NonCommercial-ShareAlike-3.0 License, which permits use, distribution and reproduction for non-commercial purposes, provided the original is properly cited and derivative works building on this content are distributed under the same license. 